\title{
5 Thin Coating Technologies and Applications in High-Temperature Solid Oxide Fuel Cells
}

\author{
San Ping Jiang
}

\section{CONTENTS}

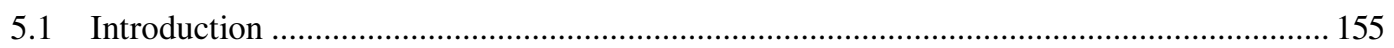

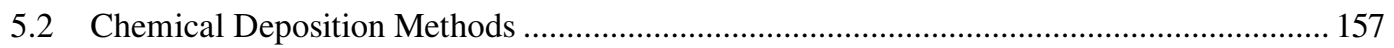

5.2.1 Chemical Vapor Deposition and Atomic Layer Deposition ................................... 157

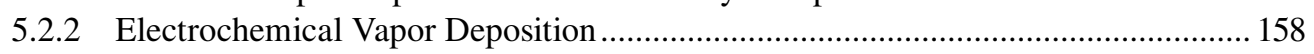

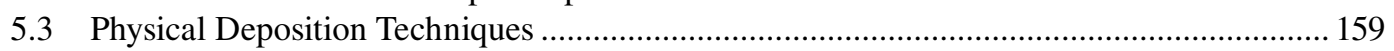

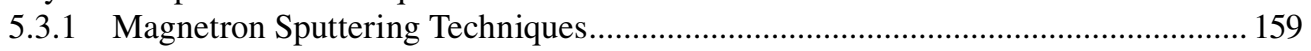

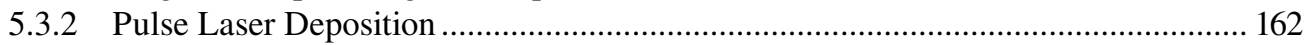

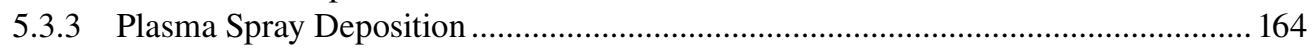

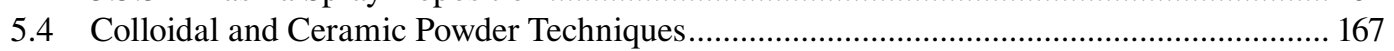

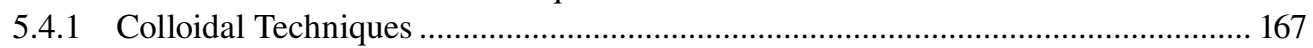

5.4.1.1 Slurry-Coating, Spin-Coating, and Dip-Coating Methods........................ 167

5.4.1.2 Sol-Gel Method................................................................................... 169

5.4.1.3 Screen-Printing Method...................................................................... 170

5.4.1.4 Electrophoretic Deposition .................................................................... 171

5.4.2 Ceramic Powder Techniques …............................................................................ 173

5.4.2.1 Tape-Casting and Freeze-Tape-Casting Process ....................................... 173

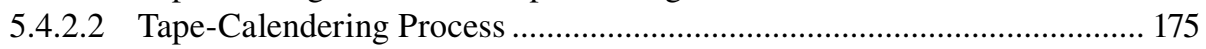

5.4.2.3 Dry-Pressing Method ............................................................................ 175

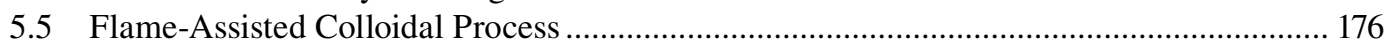

5.5.1 Spray Pyrolysis and Flame-Assisted Vapor Deposition .......................................... 176

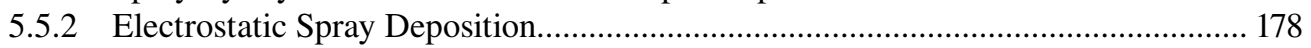

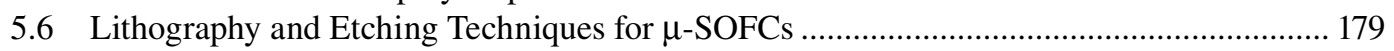

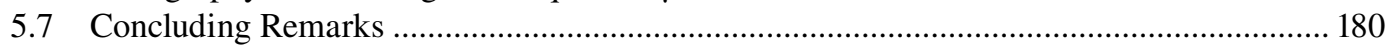

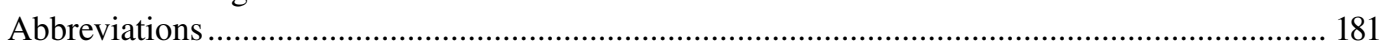

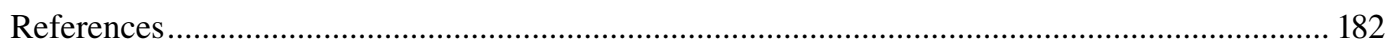

\subsection{INTRODUCTION}

A solid oxide fuel cell (SOFC) is an electrochemical device to convert the chemical energy of fuels, such as hydrogen and hydrocarbons, to electricity, with potential applications in transportation, distributed generation, remote power, defense, and many others [1-3]. They offer extremely high chemical-to-electrical conversion efficiencies because the efficiency is not limited by the Carnot 


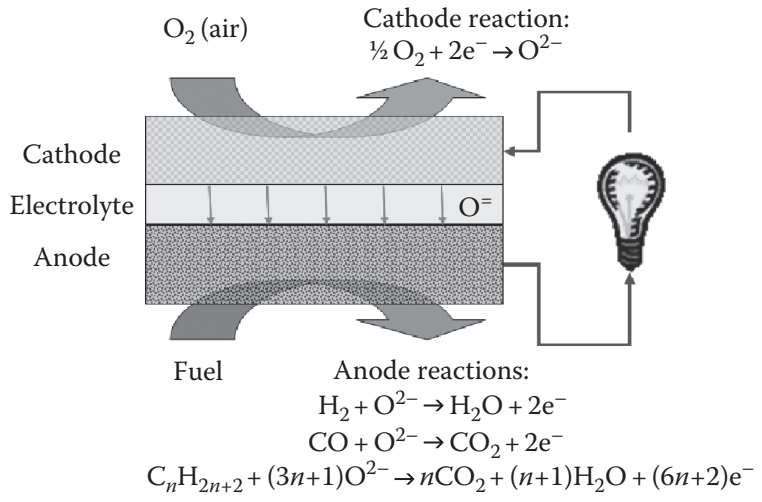

FIGURE 5.1 Schematic diagram of a solid oxide fuel cell. (From Jiang, S.P., J. Mater. Sci., 43, 6799, 2008. With permission.)

cycle of a heat engine. Further energy efficiency can be achieved when the produced heat is used in combined heat and power, or gas turbine applications. Furthermore, the greenhouse gas emission from an SOFC is much lower than that from conventional power generation technologies. Due to its high operating temperature, an SOFC has a high tolerance to typical catalyst poisons, produces high-quality heat for reforming of hydrocarbons, and offers the possibility of direct utilization of hydrocarbon fuels.

An individual SOFC cell is composed of a porous anode or fuel electrode, a fully dense solid electrolyte, and a porous cathode or air electrode (see Figure 5.1) [4]. Driven by the differences in oxygen chemical potential between fuel and air compartments of the cell, oxygen ions migrate through the electrolyte to the anode where they are consumed by oxidation of fuels such as hydrogen, methane, and hydrocarbons $\left(\mathrm{C}_{n} \mathrm{H}_{2 n+2}\right)$. Thus, the electrolyte must be dense in order to separate the air and fuel, must possess high oxygen ionic conductivity but negligible electronic conductivity, and must be chemically and structurally stable over a wide range of partial pressure of oxygen and temperatures [5]. On the other hand, the cathode and anode must be porous, chemically and thermally compatible with the electrolyte and interconnect, and be electrocatalytically active for the oxygen reduction and fuel oxidation reaction, respectively. In the case of hydrocarbon fuels, the anode must also possess certain tolerance toward sulfur and carbon deposition under SOFC operating conditions. Yttria-stabilized zirconia (YSZ) is the most commonly used solid electrolyte, while lanthanum strontium manganite (LSM) and nickel-YSZ often serve as the cathode and anode, respectively. Issues facing the development of electrode materials of SOFC have been reviewed $[4,6,7]$.

Traditional SOFCs operate at high temperatures $\left(900^{\circ} \mathrm{C}-1000^{\circ} \mathrm{C}\right)$ because of the low oxygen ion conductivity and high activation energy of oxide electrolytes such as YSZ. However, lowering of the operating temperature of SOFCs brings both dramatic technical and economic benefits. The cost of an SOFC system can be substantially reduced by using less costly metal alloys as interconnect and compliant temperature gaskets [8]. Furthermore, as the operation temperature is reduced, thermodynamic efficiency, system reliability, and durability of cell performance increase. This increases the possibility of using SOFCs for a wide variety of applications, including residential and automotive applications. On the other hand, reduction in operation temperature results in a significant increase in the electrolyte and electrode resistivity and the polarization losses. To compensate for the performance losses associated with a lower operating temperature, the thickness of electrolyte layer has to be reduced in order to lower the ohmic resistance of the cell. Using a thin electrolyte layer, the electrolyte can no longer mechanically support the cell. Thus, anode- or cathode-supported structures need to be employed. Anode-supported structure based on Ni/YSZ or Ni/GDC (Gd-doped ceria) 
cermets is the most popular one for the deposition of a thin electrolyte film on a thick, mechanically strong, and porous anode substrate.

The state-of-the-art anode-supported SOFC is based on porous Ni/YSZ cermets as a support. The anode support usually consists of a relatively thick porous supporting substrate and a thin and fine structured electrode layer, the anodic function layer (AFL). To reduce the electrolyte ohmic resistance and to enhance the cell efficiency, the electrolyte layer deposited should be as thin as possible. In addition, the thin electrolyte layer on the Ni/YSZ anode porous substrate/support should also have (1) high ionic conductivity, (2) high density and uniformity to minimize the fuel or oxidant crossover, (3) enough mechanical strength to resist high gas pressure gradient, and (4) good chemical and thermal compatibility with the anode as well as cathode without forming resistive phases at the electrode-electrolyte interface. Deposition techniques for the fabrication of thin and dense electrolyte films for SOFCs were reviewed by Will et al. [9].

Chromia-forming ferric stainless steel has been considered to be the primary candidate as the interconnect material for SOFCs for the intermediate temperature SOFCs, IT-SOFC, due to the economic and easy processing benefits. However, chromia-forming alloy forms a chromium oxide scale at the SOFC operation temperature. Without effective protective coating, the vaporization of chromium species poisons the cathode of SOFCs and seriously degrades the cell performance [10]. To reduce the growth rate of the oxide scale and the vaporization of chromium species, a thin and dense coating is commonly deposited on the metallic interconnect. In this case, the thin coating technique should not only deliver a protective film with high density and pore free or at least with no cross pores, but also with the targeted composition and stoichiometry to ensure the high electrical conductivity.

Micro-fuel cells are a potential replacement for high efficiency and high specific energy batteries in portable power generation. To date, miniaturized fuel cells utilizing proton exchange membranes and liquid methanol fuels (i.e., direct methanol fuel cells or DMFCs) have been the primary focus of interests. However, high loading of precious metal catalysts such as Pt and PtRu is required for DMFCs to obtain the beneficial energy output due to the $\mathrm{CO}$ poisoning, and under operating conditions methanol crossover is still a serious problem [11,12]. Due to the persistent challenges with polymer-based fuel cells, there is a growing interest in the development of micro-SOFCs or $\mu$-SOFCs for portable power sources. With these systems, hydrocarbon fuels, in addition to hydrogen, can be used directly at the anode and this reduces the need for the preforming of fuels [13]. To develop $\mu$-SOFCs, the design of the support structure and the deposition techniques for the thin-film electrolyte have been the areas of challenge [14]. This chapter will focus on the most commonly used thin-film techniques for the fabrication and development of thin-film components such as electrolyte, electrode and protective coatings in SOFCs. The techniques are classified into chemical and physical methods based on the nature of the process. Examples are given for the preparation and characterization of electrolyte films as well as electrode and protective coating for metallic interconnect of SOFCs.

\subsection{CHEMICAL DEPOSITION METHODS}

Chemical methods can be further divided into chemical vapor deposition and liquid precursor techniques. There are two main chemical vapor deposition techniques: chemical vapor deposition (CVD) and electrochemical vapor deposition (EVD). These methods make it possible to control chemical composition and to form a dense film. They are also known to be suitable for mass production. Chemical methods based on liquid precursor methods will be reviewed separately in Section 5.4.1.

\subsubsection{Chemical Vapor Deposition and Atomic layer Deposition}

Chemical vapor deposition or CVD is a chemical process in which one or more gaseous precursors form a solid material by means of an activation process. CVD has been widely used for fabricating microelectronics. Therefore, the underlying processes are well understood. 


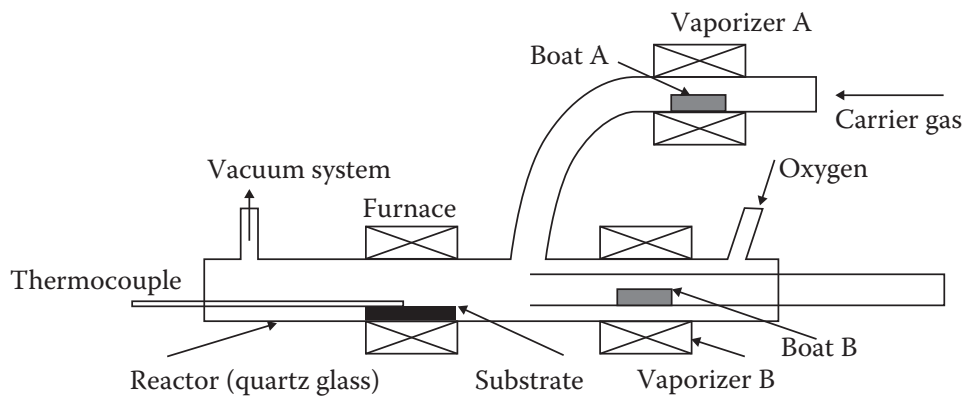

FIGURE 5.2 Schematic diagram of a CVD for preparation of $\mathrm{Y}_{2} \mathrm{O}_{3}-\mathrm{ZrO}_{2}$ films. (From Aizawa, M. et al., Nippon Seramikkusu Kyokai Gakujutsu Ronbunshi-J. Ceram. Soc. Jpn., 101, 291, 1993.)

A schematic diagram of a typical CVD apparatus is shown in Figure 5.2 [15]. Typically, fused-silica glass is used as the substrate material, which is heated to a deposition temperature of $600^{\circ} \mathrm{C}-1200^{\circ} \mathrm{C}$ depending on the reactivity of the precursors. For fabricating SOFC components, halogen compounds such as $\mathrm{ZrCl}_{4}$ and $\mathrm{YCl}_{3}[16,17]$ and metal organic compounds such as metal alkoxides [18] or $\beta$-diketones [15] have been used as precursor materials. Growth rates of the film thickness are in the range of $1-10 \mu \mathrm{m} \mathrm{h}^{-1}$, depending on the evaporation rate and substrate temperature. The capital cost for the CVD equipment is relatively high [19].

Atomic layer deposition (ALD) is a modified CVD technique. In ALD, the substrate surface is exposed alternately to different vaporized precursors. Because gaseous precursors are strictly separated from each other during deposition and the precursors have self-limiting chemistry, one reaction cycle may produce only one atomic layer. For this reason, ALD can be an ideal technique to grow ultrathin oxide films because composition of ALD films can be altered at each atomic layer with desired ratio. The growth rate for zirconia is $0.1-0.17 \mathrm{~nm} /$ cycle [20].

Prinz's group [21] fabricated freestanding ultrathin YSZ electrolyte films with a target stoichiometry, $\left(\mathrm{ZrO}_{2}\right)_{0.92}\left(\mathrm{Y}_{2} \mathrm{O}_{3}\right)_{0.08}$, by ALD. For $\mathrm{ZrO}_{2}$ and $\mathrm{Y}_{2} \mathrm{O}_{3}$, commercial tetrakis(dimethylamido)zirconium $\left(\mathrm{Zr}\left(\mathrm{NMe}_{2}\right)_{4}\right)$ and tris(methylcyclopentadienyl)-yttrium $\left(\mathrm{Y}(\mathrm{MeCp})_{3}\right)$ were used as precursors with distilled water as oxidant. ALD YSZ films were grown on a $\mathrm{Si}_{3} \mathrm{~N}_{4}$-buffered $\mathrm{Si}(100)$ wafer substrate. After ALD deposition, silicon nitride layer was removed by plasma-assisted chemical etching, leaving freestanding YSZ layers. Porous Pt layers were deposited using direct current sputtering as cathode and anode. A maximum power density of $270 \mathrm{~mW} \mathrm{~cm}^{-2}$ was reported for a cell based on an ultrathin YSZ film of $60 \mathrm{~nm}$ at $350^{\circ} \mathrm{C}$. By using corrugated thin-film YSZ electrolyte design, the maximum power density was reported to increase to $677 \mathrm{~mW} \mathrm{~cm}^{-2}$ at $400^{\circ} \mathrm{C}$ [22]. However, the success rate of the cells would be limited by the possible electric shorts between electrodes through the nanoscale electrolyte.

\subsubsection{Electrochemical Vapor Deposition}

Electrochemical vapor deposition or EVD is a modified CVD process, originally developed by Siemens Westinghouse for the fabrication of thin YSZ electrolyte layer on tubular SOFCs [23]. EVD is a two-step process. The first step involves the pore closure by a normal CVD-type reaction between the steam (or oxygen), metal chloride, and hydrogen through the porous air electrode (phase I). These react to fill the air electrode pores with the yttria-stabilized zirconia electrolyte according to the following reaction:

$$
\begin{gathered}
2 \mathrm{MeCl}_{y}+y \mathrm{H}_{2} \mathrm{O}=2 \mathrm{MeO}_{y / 2}+2 y \mathrm{HCl} \\
4 \mathrm{MeCl}_{y}+y \mathrm{O}_{2}+y \mathrm{H}_{2}=4 \mathrm{MeO}_{y / 2}+4 y \mathrm{HCl}
\end{gathered}
$$




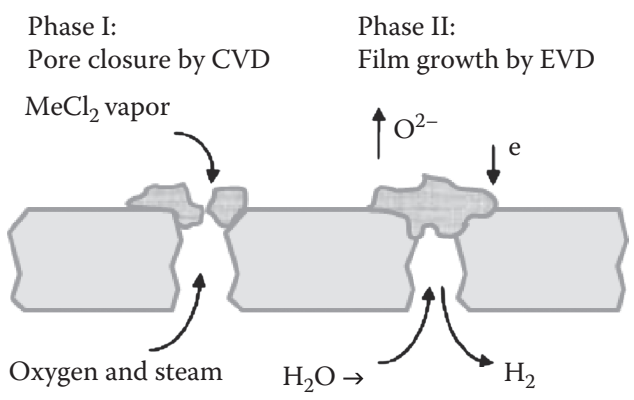

FIGURE 5.3 Schematic diagram of the EVD process. (From Pal, U.B. and Singhal, S.C., J. Electrochem. Soc., 137, 2937, 1990.)

where

Me is the cation species (zirconium and/or yttrium)

$y$ is the valence associated with the cation

After the pores in the air electrode are closed, film growth then proceeds due to the presence of an electrochemical potential gradient across the deposited film. In this step oxygen ions formed on the water vapor side of the substrate (i.e., the high oxygen partial pressure side) diffuse through the thin metal oxide layer to the metal chloride side (i.e., the low oxygen partial pressure side). The oxygen ions react with the metal chloride vapor to form the metal oxide products. The solid product or electrolyte is deposited as a thin film spreading over the internal pore surface in a desired region across the air electrode or membrane substrate. This second stage of the reaction is termed the electrochemical vapor deposition or EVD (phase II). Figure 5.3 shows the schematic diagram of the basic principles of the EVD process [23].

The growth of YSZ electrolyte film by the EVD process is parabolic with time and the rate-determining step in the EVD process was found to be the electronic transport through the electrolyte film [23]. The EVD techniques were used by others for the fabrication of thin YSZ electrolyte films and thick Ru/YSZ cermet anodes [24,25]. The dissociated oxygen from metal oxide substrates, such as $\mathrm{NiO}$, was also suggested as an oxygen source for the reaction instead of gaseous oxygen to form dense YSZ electrolyte films [26]. The effect of NiO content of the substrate on the growth rate of YSZ film was studied in detail by Kikuchi et al. [27]. The high reaction temperature, the presence of corrosive gases, and relatively low deposition rates are some of the limiting factors in the application of EVD process in SOFCs.

\subsection{PHYSICAL DEPOSITION TECHNIQUES}

Physical deposition techniques reviewed in this chapter such as magnetron sputtering, laser ablation, and plasma spray have the common feature that atoms are brought to the gas phase through a physical process from a solid or molten target. The processes include evaporation, sputtering, laser ablation, and hybrid methods. The deposited films are typically polycrystalline with columnar structure, and the grain size can be tailored by varying the deposition conditions.

\subsubsection{Magnetron Sputtering Techniques}

Magnetron sputtering is one of the most common physical deposition techniques that is widely used to grow alloy and component films in which one or more of the constituent elements are volatile. Low-defect-density films of high-melting point materials can be grown on unheated substrates because phase formation is mainly governed by kinetics, rather than by thermodynamics. 


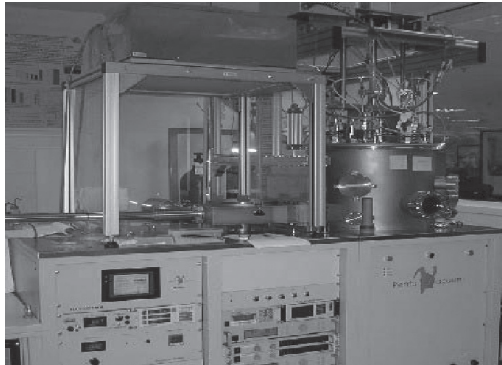

(a)

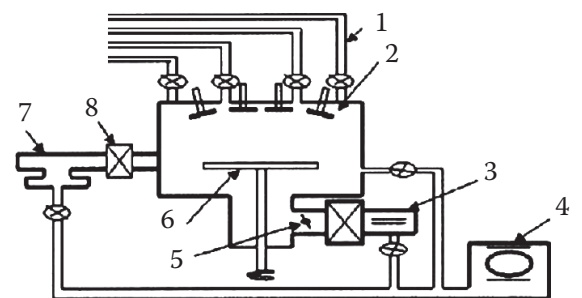

(b)

FIGURE 5.4 Outlook (a) and schematic diagram (b) of a magnetron sputtering system. In (b), 1. Gas feed line, 2. Magnetrons, 3. Cryogenic pump, 4. Rotary pump, 5. Butterfly valve, 6. Substrate holder, 7. Load lock, 8. Gate valve. (Courtesy of Dr. Liu Erjia, Nanyang Technological University, Singapore.)

Radio frequency (RF) magnetron sputtering using an oxide target and DC reactive magnetron sputtering using metallic targets have been utilized to produce YSZ thin films of high quality. RF sputtering has frequently been utilized to deposit YSZ thin films in part because of the ability to use either metallic or electrically insulating oxide target and the generally high quality of the deposit. In RF-sputtering deposition, an evacuated chamber is filled with the sputtering gas. A large negative voltage is applied to the cathode. The sputtering gas forms a self-sustained glow discharge. Physical sputtering of the target occurs when positive ions from the plasma that are accelerated across the gap strike the target surface. A metal oxide film is grown by sputtering a metal target in a discharge containing oxygen, usually in conjunction with a noble gas. The metal, metal oxide, and oxygen species that arrive at the substrate are adsorbed and ultimately incorporated into stable nuclei to form a continuous film. Oxygen is often included in the sputtering gas mixture as a means of controlling the metal to oxygen ratio in the target. However, RF-sputtering deposition rate decreases significantly with increased oxygen partial pressure [28]. Figure 5.4 shows apparatus and schematic diagram of a magnetron sputtering system.

DC current magnetron sputtering has also been widely used to deposit thin YSZ electrolyte onto porous supports [29-31]. The target can be a single target consisting of an alloy of zirconium and yttrium or can be multiple targets of the pure metal, where the composition of the deposit is controlled by the relative exposed surface area of the targets. Barnett and coworkers described the formation of fully dense YSZ thin films on porous as well as dense electrode substrates by reactive DC current magnetron sputtering with postdeposition annealing temperatures as low as $350^{\circ} \mathrm{C}[30,32]$. Electrical conductivities of the YSZ deposit were similar to those films formed by other methods. The metal-to-oxygen ratio in the deposit was found to depend critically on the oxygen partial pressure in the sputter gas. Similar to RF sputtering, deposition rates are adversely affected by the oxygen partial pressure in the sputtering gas for DC reactive magnetron sputtering of YSZ films. This behavior was shown to be particularly apparent for oxygen partial pressures less than $10 \times 10^{-4} \mathrm{mbar}$, as shown in Figure 5.5 [33]. The deposition rate dropped dramatically from $\sim 700 \mathrm{~nm} \mathrm{~h}^{-1}$ at $7.5 \times 10^{-4} \mathrm{mbar}^{-1}$ to $\sim 100 \mathrm{~nm} \mathrm{~h}^{-1}$ when the oxygen partial pressure was higher than $10 \times 10^{-4} \mathrm{mbar}$.

Surface morphology of the substrate such as pore size and pore size distribution is critical for the deposition of thin and high dense electrolyte film on the Ni/YSZ anode substrates as the morphology of the deposited film follows that of the substrate surface. Figure 5.6 shows the morphology of the YSZ film deposited on YSZ and Ni/YSZ cermet substrate by magnetron sputtering [6]. Thin YSZ film deposited is characterized by columnar structure and has the same grain and grain boundary pattern as that of the YSZ substrate (see Figure 5.6a), indicating that the surface morphology of the YSZ thin film follows closely the morphology of the substrate. The large pores on the substrate surface resulted in open pores on the YSZ electrolyte films deposited; see Figure 5.6b and c. Thus the pores diameter of the substrate surface needs to be in the order of the grain size of the deposited 


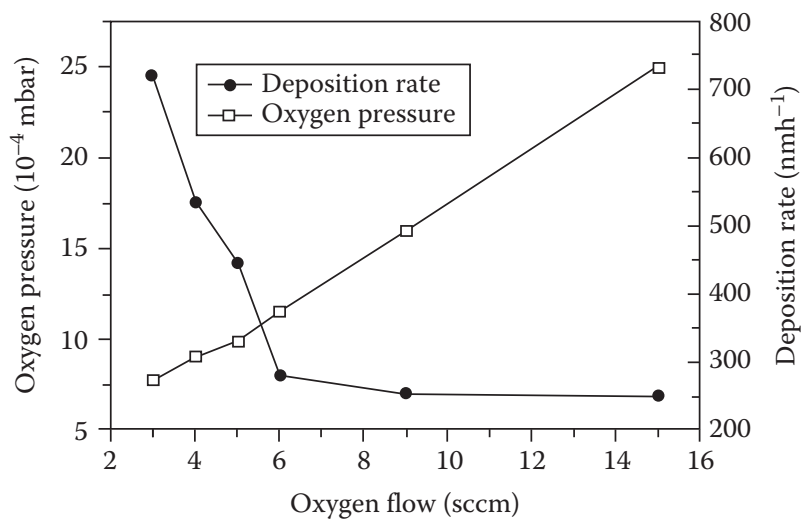

FIGURE 5.5 Relation of YSZ deposition rate by DC reactive magnetron sputtering to oxygen flow rate and oxygen partial pressure. (From Fedtke, P. et al., J. Solid State Electrochem., 8, 626, 2004.)
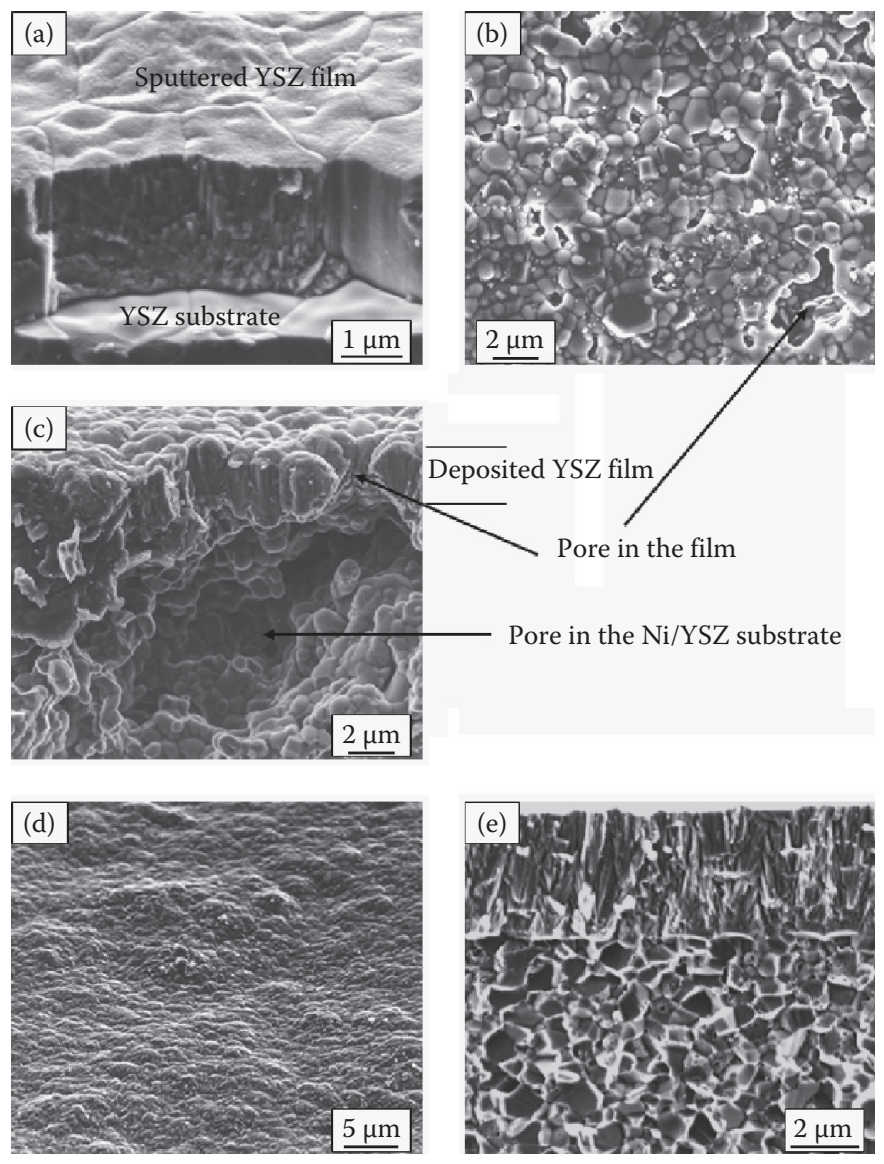

FIGURE 5.6 Morphology of the YSZ thin film deposited on YSZ and NiO/YSZ cermet anode substrate by magnetron sputtering. (a) YSZ film deposited on YSZ substrate, (b) and (c) YSZ film deposited on NiO/YSZ ceremt substrate, showing that the defects in the YSZ electrolyte film is due to the large pores on the anode substrate surface, (d) and (e) dense and uniform YSZ film on NiO/YSZ anode substrate with optimized surface morphology. (From Jiang, S.P. and Chan, S.H., J. Mater. Sci., 39, 4405, 2004. With permission.) 
film to achieve dense and uniform YSZ electrolyte films; see Figure 5.6d and e. This can be done by using an interlayer or functional layer with fine microstructure and low porosity [34]. The function layer is also used to promote the electrode reaction at the electrode-electrolyte interface [35,36].

Huang et al. [37] fabricated thin-film solid oxide fuel cell structure containing ultrathin YSZ electrolyte membrane 50-150 nm thick using RF sputtering, lithography, and etching. The porous Pt anode and cathode were deposited by DC sputtering at $10 \mathrm{~Pa}$ Ar pressure, $100 \mathrm{~W}$, and room temperature. Dense YSZ electrolyte films were deposited at $200^{\circ} \mathrm{C}$ by RF sputtering. Pt and $\mathrm{Y}_{0.16} \mathrm{Zr}_{0.84} \mathrm{O}_{1.92}$ were used as the DC and RF-sputtering targets, respectively. The maximum power density achieved is $200 \mathrm{~mW}$ $\mathrm{cm}^{-2}$ at $350^{\circ} \mathrm{C}$. DC magnetron sputtering was used by Srivastava et al. [29] to deposit YSZ electrolyte films $(5-16 \mu \mathrm{m})$ on Ni/YSZ anode substrates. In order to ensure a dense and impervious electrolyte layer it is desirable to optimize the deposition conditions such that YSZ films would remain in a state of compressive stress while adhering to the Ni/YSZ substrate. This implies that only a narrow range of deposition conditions would be suitable. The pressure in the sputtering chamber and the flow of oxygen close to the critical zone during deposition were shown to be important parameters and required careful control [29]. Magnetron sputtering was also used to deposit a GDC protecting layer on YSZ electrolyte to prevent $\mathrm{Sr}^{2+}$ migration from $(\mathrm{La}, \mathrm{Sr})(\mathrm{Co}, \mathrm{Fe}) \mathrm{O}_{3}$ cathode toward the $\mathrm{YSZ}$ electrolyte [38].

Magnetron sputtering techniques combined with photolithography are used to produce unique, patterned electrodes such as LSM, Ni, platinum, and gold. The patterned, thin, dense, and uniformly structured electrodes allow the fundamental aspects of the reaction mechanism to be studied, which is not possible with conventional, heterogeneous, porous electrode structure. Horita et al. [39] studied the active site distribution of the $\mathrm{O}_{2}$ reduction reaction on patterned LSM electrodes and demonstrated by SIMS that the $\mathrm{O}_{2}$ reduction reaction occurs primarily at the three phase boundaries (TPB) where LSM cathode, oxygen reactant gas, and TSZ electrolyte meet. The linear relation between the length of TPB and the rate of the reaction was also found for the $\mathrm{H}_{2}$ oxidation reaction on patterned $\mathrm{Ni}$ anodes of SOFCs [40]. Sputtering method is also used to prepare protective coating for metallic interconnect. Lee and Bae [41] applied RF magnetron sputtering technique to deposit $\mathrm{La}_{0.6} \mathrm{Sr}_{0.4} \mathrm{CrO}_{3}$ (LSCr) and $\mathrm{La}_{0.6} \mathrm{Sr}_{0.4} \mathrm{CoO}_{3}$ (LSCo) as an oxidant-resistant coating on $\mathrm{Fe}-\mathrm{Cr}$ ferric stainless steel SS430. The oxide layer shows dense structure and good adhesion to the SS430 alloy. LSCr-coated SS430 has a low electrical resistance as compared to LSCo-coated SS430 probably due to the low diffusivity of manganese or chromium in the LSCr layer. The RF magnetron sputtered lanthanum chromite film on a stainless steel substrate formed the orthorhombic perovskite structure after being annealed at $700^{\circ} \mathrm{C}$, and exhibited a dendritic microstructure [42].

\subsubsection{Pulse laser Deposition}

Pulse laser deposition (PLD) or laser ablation is a physical method of thin-film deposition in which a pulsed laser beam, usually of wavelength in the UV range, is employed to ablate a target composed of the desired thin-film composition, which is subsequently deposited onto a substrate. The usual range of laser wavelengths for thin film growth by PLD lies between 200 and $400 \mathrm{~nm}$ for most materials. In PLD, the temperature of the substrate is one of the main parameters affecting atomic surface mobility during the deposition process. PLD enables fabrication of multicomponent stoichiometric films from a single target, and with an appropriate choice of the laser (e.g., Nd:YAG, $\mathrm{KrF}, \mathrm{XeCl}$ ), any material can be ablated and the growth can be carried out in a pressure of any kind of gas, reactive or not. Shown in Figure 5.7 is the schematic diagram of a pulse laser deposition process using $\mathrm{KrF}$ excimer laser [43].

The microstructure of the PLD films depends on the substrate temperature and pressure. Mengucci et al. [44] reported the formation of dense YSZ films by PLD at room temperature and oxygen pressure below 0.05 mbar. On the other hand, highly porous YSZ films can be obtained at high pressure of 0.3 mbar [45]. Infortuna et al. [46] studied in detail the characteristics of YSZ and GDC thin films by PLD and the microstructure of GDC and YSZ thin films deposited ranges from highly porous to dense depending on the substrate temperature and oxygen pressure during the 


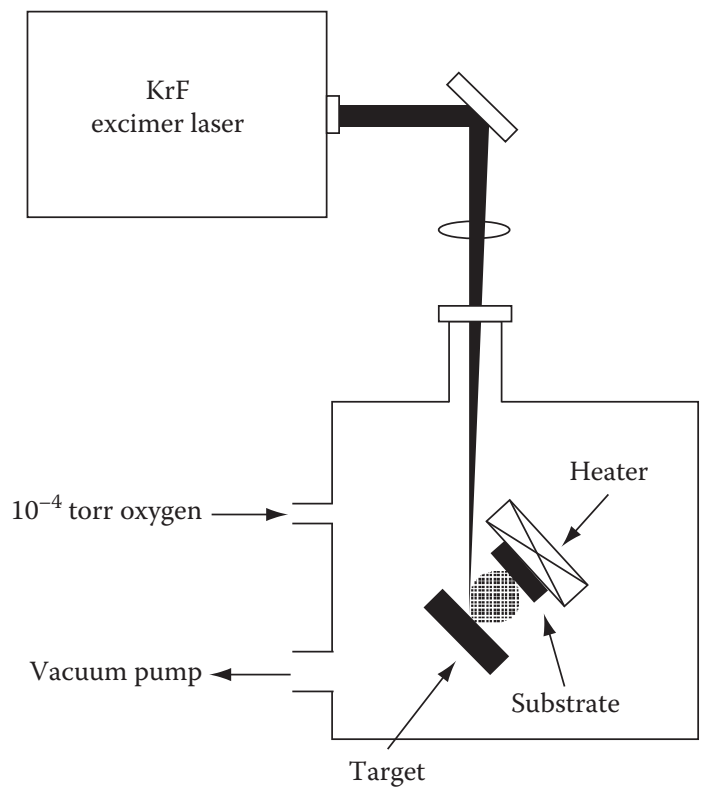

FIGURE 5.7 Schematic diagram of a pulse laser deposition process using KrF excimer laser. (From Suzuki, M. et al., Solid State Ionics, 96, 83, 1997.)

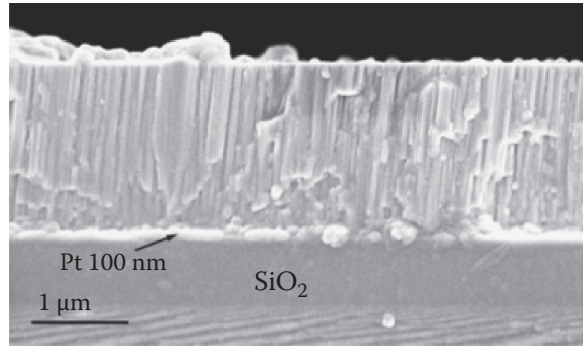

(a)

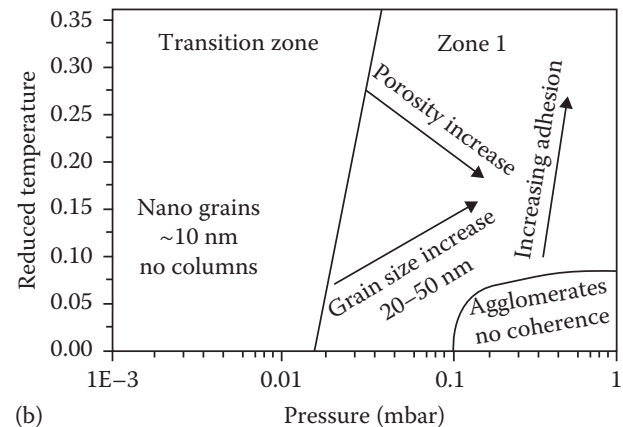

(b)

Pressure (mbar)

FIGURE 5.8 SEM micrograph of a dense YSZ thin film deposited at $800^{\circ} \mathrm{C}$ under 0.026 mbar oxygen pressure on a $\mathrm{Si} / \mathrm{SiO}_{2} / \mathrm{TiO}_{2} / \mathrm{Pt}$ substrate (a); and structural map for GDC and YSZ thin film deposited by PLD (b). The normalized deposition temperature was calculated from the melting temperature of the materials $\left(2500^{\circ} \mathrm{C}\right.$ was used for both YSZ and GDC). (From Infortuna, A. et al., Adv. Funct. Mater., 18, 127, 2008.)

deposition process. Figure 5.8 shows a typical SEM micrograph of a dense YSZ thin film deposited at $800^{\circ} \mathrm{C}$ and structure map for GDC and YSZ thin films deposited by PLD [46]. The electrical conductivity of the PLD films appears to be lower than that of the bulk materials. For example, the conductivity of a thin YSZ film deposited at $400^{\circ} \mathrm{C}$ in $0.026 \mathrm{mbar}$ is $3 \times 10^{-4} \mathrm{~S} \mathrm{~cm}^{-1}$ at $500^{\circ} \mathrm{C}$, significantly lower than the conductivity value of $\sim 10^{-3} \mathrm{~S} \mathrm{~cm}^{-1}$ for single YSZ crystal. Low electrical conductivity for YSZ thin films by PLD is also reported by Joo and Choi [47]. One potential problem is that PLD techniques result in crystalline microstructures that usually show columnar grains and texture, resulting in unfavorable anisotropic electrical conductivity [48]. Similar to the magnetron sputtering techniques, the surface artifacts of the function layer should also be smaller than the film thickness in order to avoid the defects on the YSZ film deposited by PLD technique [49].

PLD has been used to deposit multielement films such as LSM for SOFC [50]. Due to its unique method of dislodging atoms from the target, PLD provides some distinct advantages among thin-film 
techniques. Due to the weak interaction of lasers with gaseous species, ambient atmospheres can be used with little contamination, a significant advantage as compared to other deposition techniques based on ions or electrons. Thus, stoichiometric materials transfer from the target to the substrate could be achieved. Koep et al. [51] studied microstructure and electrochemical properties of LSM and LSC prepared by PLD. Deposition of LSM above $500^{\circ} \mathrm{C}$ results in thin films in the orthorhombic phase while the low-temperature-grown LSM films are amorphous. The stoichiometry of the film is the same as the target composition and the conductivity of the LSM dense film is $21 \mathrm{~S} \mathrm{~cm}^{-1}$ at $700^{\circ} \mathrm{C}$. Microfabrication process in combination of photolithographic process is also used to produce well-defined three-dimensional geometries for the investigation of electrode reaction process and reaction sites at LSM electrode materials [52]. PLD is also used to fabricate cobalt and ferritebased perovskite cathodes such as $\mathrm{La}_{0.6} \mathrm{Ca}_{0.4} \mathrm{Fe}_{0.8} \mathrm{Ni}_{0.2} \mathrm{O}_{3-x}$ (LSFN) [53] and (La,Sr) $\mathrm{CoO}_{3}$ (LSCo) [54] on YSZ electrolyte because the crystalline phase of the perovskite can be formed at substrate temperature of $700^{\circ} \mathrm{C}$ to avoid the interfacial reaction between YSZ and lanthanum cobaltite-based cathodes. Reasonable area specific resistance (ASR) of $1.59 \Omega \mathrm{cm}^{2}$ at $850^{\circ} \mathrm{C}$ was reported on the LSFN dense cathode layer by PLD [53]. Due to the dense structure of the PLD films, PLD method would be best suitable for the electrode application with high mixed ionic and electronic conducting oxides. For example, for the LSM cathode films prepared by PLD, the ASR can be as high as $32.1 \Omega$ $\mathrm{cm}^{2}$ at $850^{\circ} \mathrm{C}$ [55]. This is due to the fact that LSM is an electronic conductor with negligible oxygen ion conductivity. PLD is also used to deposit $\mathrm{La}_{0.8} \mathrm{Sr}_{0.2} \mathrm{Cr}_{0.97} \mathrm{~V}_{0.03} \mathrm{O}_{3}$ and $\mathrm{MnCr}_{2} \mathrm{O}_{4}$ protective films on Crofer 22APU interconnect at a substrate temperature of $750^{\circ} \mathrm{C}$ [56]. The deposited films were dense and significantly reduced the growth of the oxide scale of the alloy.

Another technique suitable for large-scale production for industrial purpose is electron beamphysical vapor deposition (EB-PVD). EB-PVD is a reliable technique for the deposition of thin film by the vacuum evaporation of a target using an electron-beam heating device. This technique has the advantages of the deposited films with an exact target composition, having high deposition rates at low temperatures, and realizing large-scale production for industrial application. The deposition rates of EB-PVD are typically in the range $1-2 \mu \mathrm{m} \mathrm{min}^{-1}$. In addition, this method can make the deposited film crystallized without additional annealing, thus saving time and energy in the manufacturing process. Another variation of PLD is the large area filtered arc deposition (LAFAD), which has been applied to deposit protective thin coatings on Cr-Fe alloys using CoMn and CrAIY target alloys [57].

Jung et al. [58] investigated the deposition and characteristics of the YSZ thin films deposited on $\mathrm{Ni} / Y S Z$ anode supports using EB-PVD technique. The YSZ target for the electron-beam deposition was prepared by conventional uniaxial pressing with commercial YSZ powder under 30 MPa followed by sintering in air at $1400^{\circ} \mathrm{C}$ for $5 \mathrm{~h}$. The grain size of the YSZ film before heat treatment is $0.5-1 \mu \mathrm{m}$ and grows to very dense columns with a grain size of $1-2 \mu \mathrm{m}$. Heat treatment improves the densification and the adhesion of the YSZ film with the anode functional layer. The results indicate that the electrical conductivity of EB-PVD YSZ electrolyte is smaller than that of the bulk YSZ at temperatures higher than $600^{\circ} \mathrm{C}$ [59]. The higher electrical resistance of the YSZ film deposited by EB-PVD could cause additional internal ohmic losses of the cell operating in the intermediate temperatures above $600^{\circ} \mathrm{C}$. The maximum power density for an anode-supported YSZ thin electrolyte cell prepared by EB-PVD was $0.78 \mathrm{~W} \mathrm{~cm}{ }^{-2}$ at $800^{\circ} \mathrm{C}$. EB-PVD was also used to deposit GDC thin films on porous NiO/YSZ anode substrates [60]. The main dominating crystallite orientation of the GDC film repeats the characteristics of the used powder, and the crystalline size of the GDC thin film is influenced by the e-beam gun power.

\subsubsection{Plasma Spray Deposition}

The plasma spray process is a high-temperature process (up to $15,000 \mathrm{~K}$ for a typical DC torch operating at $40 \mathrm{~kW}$ ). Figure 5.9 are the schematic diagrams of DC and RF plasma spray processes [61]. The plasma spray process is based on the generation of a plasma jet consisting of argon or 


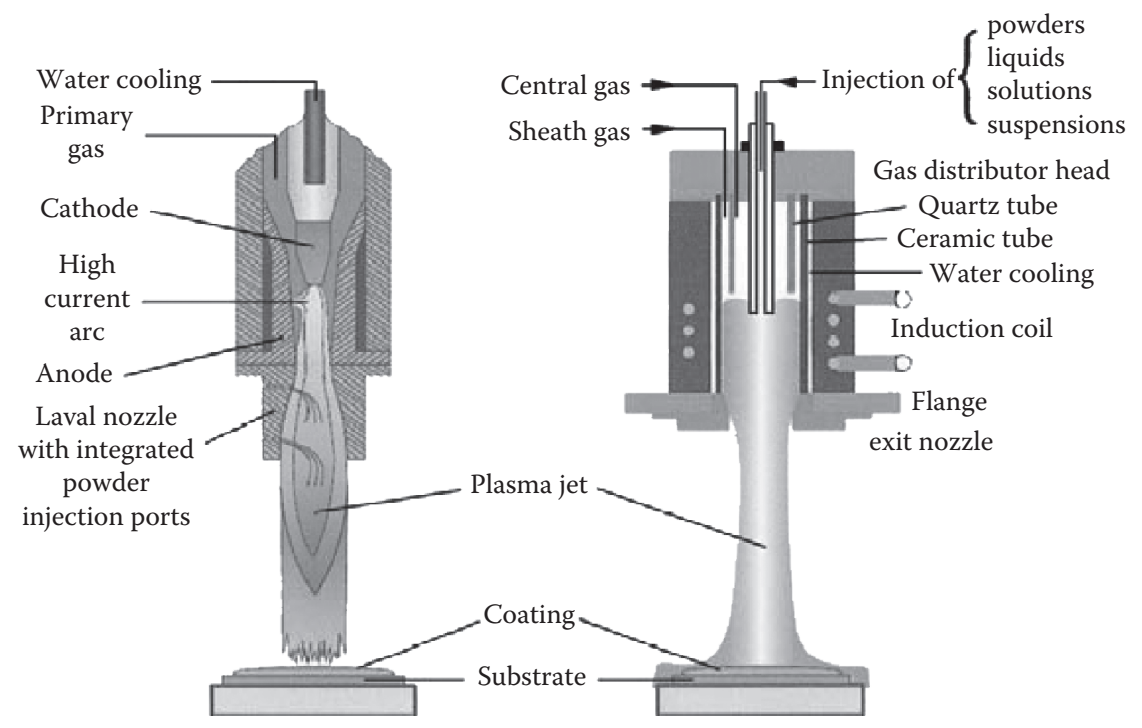

FIGURE 5.9 Schematic diagrams of DC and RF plasma spray processes. (From Pederson, L.R. et al., Vacuum, 80, 1066, 2006.)

argon with mixture of $\mathrm{H}_{2}$ and $\mathrm{He}$, which are ionized by a high-current arc discharge in a plasma torch. The powders to be sprayed are injected into the plasma where they are accelerated, melted, and finally projected onto a substrate. The coating is formed by solidification and flattening of the particles at impact on the substrate. This technique offers the possibility to deposit thin or thick layers in the millimeter range, which is hardly possible with other physical methods such as magnetron sputtering and PLD. With thermal spray technology, cells could be produced without using time and energy consuming sintering steps, reducing the production cost of SOFCs. The deposited layers often show the characteristics of anisotropic microstructure, microcracks due to thermal stress, and interlamellar porosity. The films produced by vacuum plasma spray (VPS) typically posses higher density than those produced by atmosphere plasma spray (APS) [62]. Thus VPS becomes particularly important in fabrication of the SOFC electrolyte.

Tai and Lessing [63] used plasma spray to prepare porous LSM electrodes. Addition of pore formers, such as carbon, is necessary for spraying a porous coating. Coatings with a porosity of $\sim 40 \%$ were deposited from LSM with a broad particle size distribution of $53-180 \mu \mathrm{m}$ and $15 \mathrm{wt} \%$ solid Carbospheres as a pore former. The microstructure of the plasma-sprayed LSM coating is characterized by large agglomerates and coarse porous structure; see Figure 5.10.

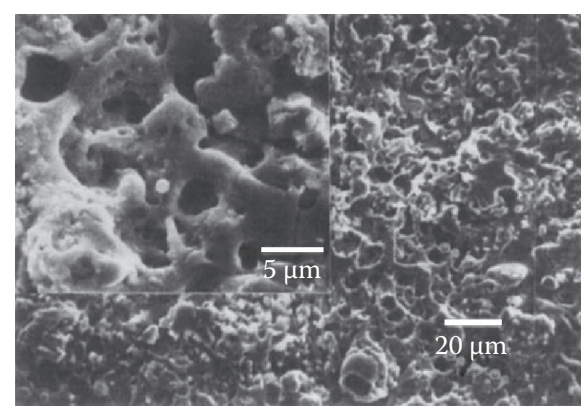

FIGURE 5.10 SEM micrograph of an annealed LSM coating plasma-sprayed from a mixture of broad-sized LSM and $15 \mathrm{wt} \%$ type-S130 Carbospheres as pore former. (From Tai, L.W. and Lessing P.A., J. Am. Ceram. Soc., 74, 501, 1991.) 
Li et al. [64] studied the effect of spray parameters such as plasma power and spray distance on the electrical conductivity of plasma-sprayed LSM coating and observed lower conductivity compared to that of the sintered LSM. This is explained by the formation of a lamellar structure of the plasma-sprayed LSM coating. The disadvantage of the method is that rapid heating and quenching involved induces nonstoichiometry and residual strain. Post treatment, e.g., at $1000^{\circ} \mathrm{C}$ in air for $2 \mathrm{~h}$, was shown to be able to recover the crystallinity and stoichiometry of the plasma-sprayed LSM coating [65] and to increase the electrical conductivity [64]. Rambert et al. [66] prepared LSM/YSZ composite cathodes using the VPS technique. The performance of the LSM/YSZ composites is affected by the mixing process of the powders. Van herle et al. [67] prepared YSZ electrolyte by VPS and observed a strong anisotropy in the ionic conductivity of YSZ electrolytes. The cross-plane conductivities are several times lower than in-plane conductivities. This anisotropy can be eliminated by sintering the deposited YSZ layer at $1500^{\circ} \mathrm{C}$ for $2 \mathrm{~h}$. The processing parameters such as the heat treatment, melting temperature of the raw materials, and particle size distribution have been shown to have a significant influence in the microstructure and conductivities of the films $[68,69]$.

More recently, there have been attempts to fabricate SOFCs and LSM/YSZ composite cathodes on metallic substrates using APS, taking advantage of the relative simple and low cost of this process [70,71]. Vassen et al. [72] applied APS to fabricate porous NiO/YSZ coatings for anode, dense YSZ coatings for electrolyte, and functional coatings for reducing Cr-evaporation from interconnects. Figure 5.11 shows the cross section of a NiO/YSZ layer deposited on a tape-casted Chrofer APU22 metallic support using APS [72]. Some layer formation is still visible in the coating, indicating that the injection process needs to be further optimized. Under SOFC operation condition the $\mathrm{NiO}$ will be reduced to $\mathrm{Ni}$ and additional pores will be formed. A dense YSZ layer was deposited onto this anode layer. In order to achieve the dense microstructure of the YSZ electrolyte layer, the velocity and temperature of the fused and crushed YSZ powder have to be high, the speed and temperatures are close to $320 \mathrm{~m} \mathrm{~s}^{-1}$ and $\sim 3200^{\circ} \mathrm{C}$. A cell with APS-deposited NiO/YSZ anode and YSZ electrolyte and screen-printed LSM cathode produced a power density of $0.8 \mathrm{~W} \mathrm{~cm}^{-2}$ at $800^{\circ} \mathrm{C}$. By using high-speed plasma torches and specially designed nozzles, thin and gastight yttria- and scandia-stabilized $\mathrm{ZrO}_{2}$ (YSZ and ScSZ) electrolyte layers $(\sim 30 \mu \mathrm{m}$ in thickness and $1.5 \%-2.5 \%$ in porosity) and of porous electrode layers with high material deposition rates were fabricated by VPS techniques. The plasma-sprayed metal-supported cells showed good electrochemical performance and low internal resistances. Power densities of $300-400 \mathrm{~mW} \mathrm{~cm}^{-2}$ at $750^{\circ} \mathrm{C}-800^{\circ} \mathrm{C}$ were reported for plasma-sprayed cells $[73,74]$.
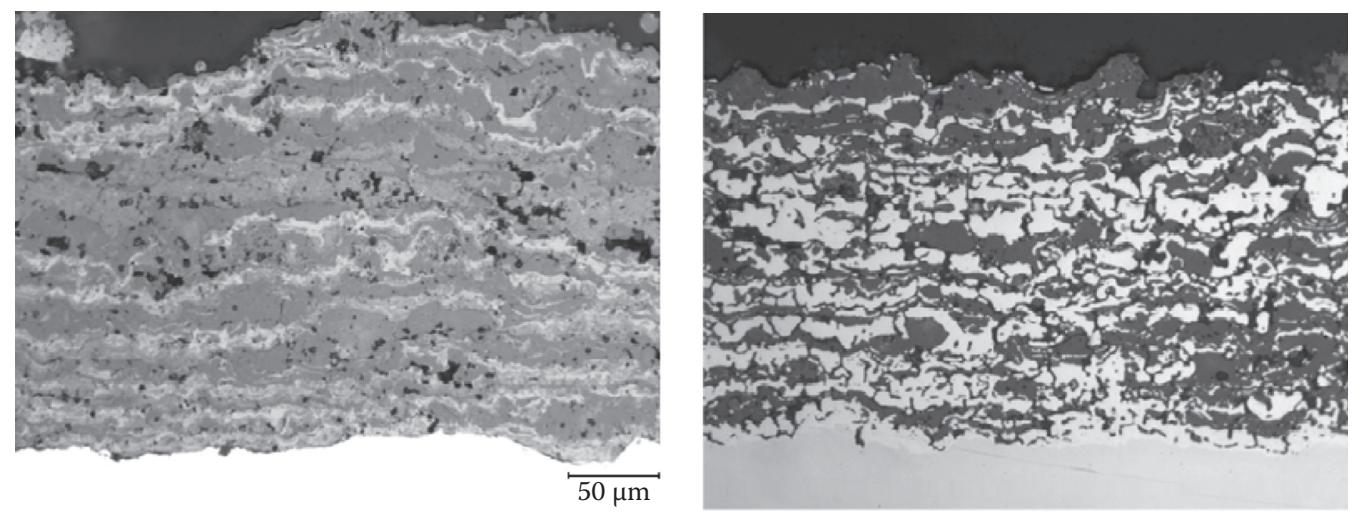

FIGURE 5.11 SEM micrographs of cross section of NiO/YSZ anode layer deposited on ferritic steel substrate (on the right reduced). (From Vassen, R. et al., Surf. Coat. Technol., 202, 4432, 2008.) 


\subsection{COLLOIDAL AND CERAMIC POWDER TECHNIQUES}

Colloidal and ceramic powder techniques are simple and cost-effective methods for the manufacturing of thin electrolyte films. The colloidal and ceramic powder methods include tape casting [75,76], slurry coating [77,78], spin coating [79,80], dip coating, screen-printing [81,82], etc.

\subsubsection{Colloidal TechniQues}

\subsubsection{Slurry-Coating, Spin-Coating, and Dip-Coating Methods}

In the case of slurry coating, spin coating and dip coating, additives such as dispersant and surfactants are added to the electrode or electrolyte powder in order to form a suitable and stable colloidal particle suspension. Moreover, in order to avoid cracks during removal of the organic additives, careful drying and heat treatment procedures have to be adopted. Figure 5.12 shows the schematic diagram for spin-coating and dip-coating apparatus. The process is simple and requires little investment. However, the coating process needs to be repeated several times to form a dense and pore-free thin electrolyte layer.

Chen et al. [83] prepared YSZ slurry mixed with ethyl cellulose and terpineol in a weight ratio of 25:3.4:71.6. The results indicate that heat treatment at $400^{\circ} \mathrm{C}$ for $10 \mathrm{~min}$ for each spin coated layer is effective to remove the organic additives and to form a dense YSZ layer by repeated spin coating process. A single cell with a $14 \mu \mathrm{m}$ thick YSZ film and Sm-doped ceria (SDC)-impregnated LSM cathode yields a maximum power density of $634 \mathrm{~mW} \mathrm{~cm}^{-2}$ at $700^{\circ} \mathrm{C}_{\text {in }} \mathrm{H}_{2}$ /air. YSZ electrolyte layer as thin as $0.5 \mu \mathrm{m}$ was prepared by the spin coating method using YSZ precursors containing zirconia chloride hydroxide and yttrium chloride hydroxide as the source of $\mathrm{Zr}$ and $\mathrm{Y}$ with polyvinylpyrrolidone (PVP) additive [84]. Dense and gastight YSZ films were obtained after repeating the spin coating process three times (see Figure 5.13). Spin coating was also used for the preparation of thin porous $\mathrm{Sm}_{0.5} \mathrm{Sr}_{0.5} \mathrm{CoO}_{3}$ (SSC) cathode for SOFCs, using a suspension solution made from SSC powder and ethyl cellulose in ethanol [85]. The suspension was applied to the doped ceria electrolyte surface and spun at $6000 \mathrm{rpm}$ for $30 \mathrm{~s}$ to form a uniform layer and to remove the solvent. To form $\sim 20 \mu \mathrm{m}$ thick SSC cathode, 50 spin coating cycles were performed [85]. However, by combination of thick slurry coating and thinning and smoothing with a spinning step, a thin and dense YSZ electrolyte layer can be fabricated by a single coating-drying cycle [86].

Aerosol spray deposition was also used to fabricate YSZ thin electrolyte films on metal-supported structure from an isopropanol-based solution [87]. A metal-supported SOFC with thin YSZ electrolyte film achieved a maximum power density of $332 \mathrm{~mW} \mathrm{~cm}^{-2}$ with $\mathrm{H}_{2} /$ air at $700^{\circ} \mathrm{C}$ [88]. Wang et al. [89] described a fabrication process for the Ni/YSZ anode-supported thin-film YSZ cells based on tape casting and spray coating. The Ni/YSZ tape-cast green tapes were cut to desired size and annealed in air at $\sim 1000^{\circ} \mathrm{C}$ for $1 \mathrm{~h}$ to obtain porous substrate with a thickness between 200 and $250 \mu \mathrm{m}$. The YSZ thin-film electrolyte was then deposited by spray coating a YSZ-water suspension on substrates under controlled conditions and sintered at $1400^{\circ} \mathrm{C}$ for $4 \mathrm{~h}$. YSZ electrolyte film as thin
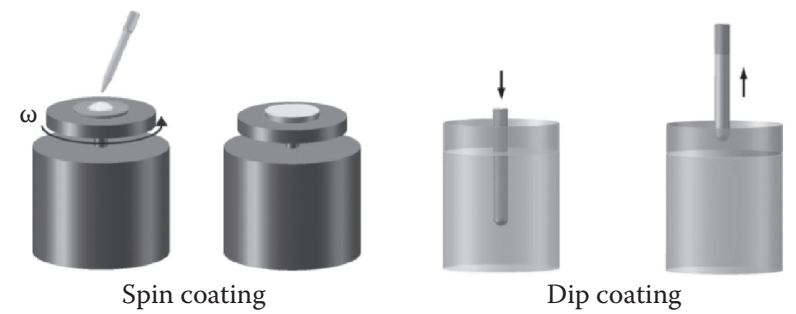

Dip coating

FIGURE 5.12 Schematic diagrams of spin-coating and dip-coating processes. 

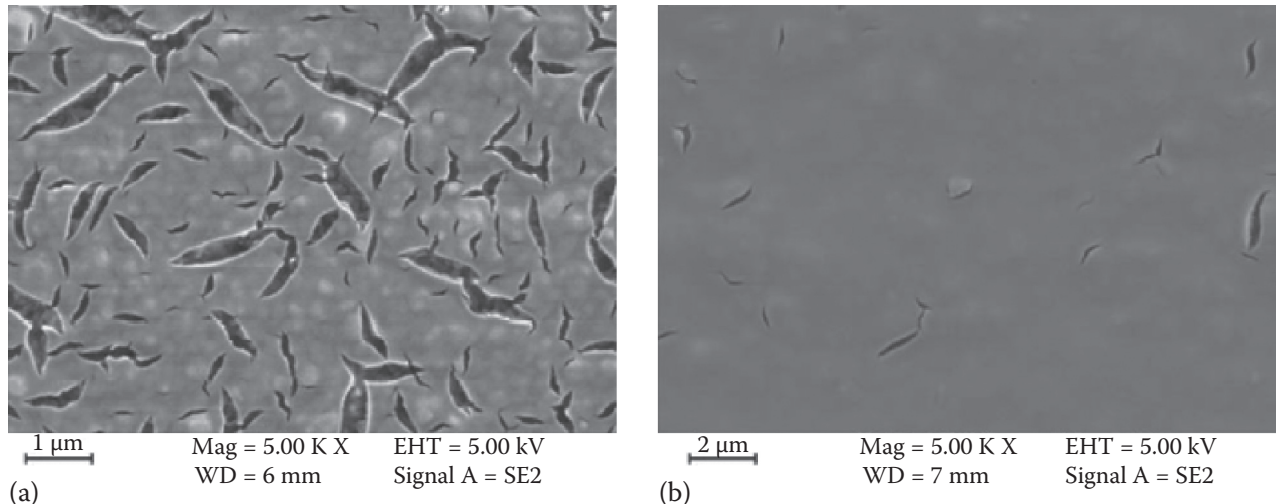

FIGURE 5.13 SEM micrographs of the surface of YSZ-coated samples after heat treatment at $600^{\circ} \mathrm{C}$ : One spin coating (a) and three spin coatings (b). (From Chen, Y.Y. and Wei, W.C.J., Solid State Ionics, 177, 351, 2006.)

as $3 \mu \mathrm{m}$ can be obtained. The cell shows a very low ASR, $0.071 \Omega \mathrm{cm}^{2}$ at $800^{\circ} \mathrm{C}$, and has a power output of $0.85 \mathrm{~W} \mathrm{~cm}^{-2}$ at $800^{\circ} \mathrm{C}$.

Slurry or dip coating has been used extensively for the fabrication of dense YSZ electrolyte [9]. Zhang et al. used the slip-casting method in combination with dip coating to fabricate anodesupported tubular SOFCs [90]. The Ni/YSZ anode tube support was prepared by the slip-casting method and presintered at $1000^{\circ} \mathrm{C}$ for $2 \mathrm{~h}$. The anode functional layer (AFL) and YSZ electrolyte thin film were prepared by dip coating. A suspension of $10 \mathrm{wt} \% \mathrm{NiO} / \mathrm{YSZ}$ (NiO:YSZ = 1:1 by weight) in isopropanol was dip coated onto the anode tubular substrate to form AFL. Similarly, a suspension of $10 \mathrm{wt} \%$ YSZ in isopropanol was dip coated onto the outer surface of the anode functional layer to form an electrolyte layer, followed by drying at room temperature. The process was repeated 10 times in order to prepare a dense and pore-free YSZ thin electrolyte layer. The YSZ-coated NiO/ YSZ tubular substrate tubes were sintered at $1380^{\circ} \mathrm{C}$ for $2 \mathrm{~h}$ to form a bilayer structure with a porous anode substrate and a dense electrolyte thin film. Multilayered cathodes of LSM, LSM/YSZ, and $\mathrm{Sm}_{0.5} \mathrm{Sr}_{0.5} \mathrm{O}_{3}$ (SSC) were deposited on a thin YSZ electrolyte by dip-coating method. Figure 5.14 shows SEM micrographs of an anode-supported tubular cell with a thin YSZ film and a multilayered cathode prepared by dip-coating method. With impregnation of nano-sized GDC particles into both
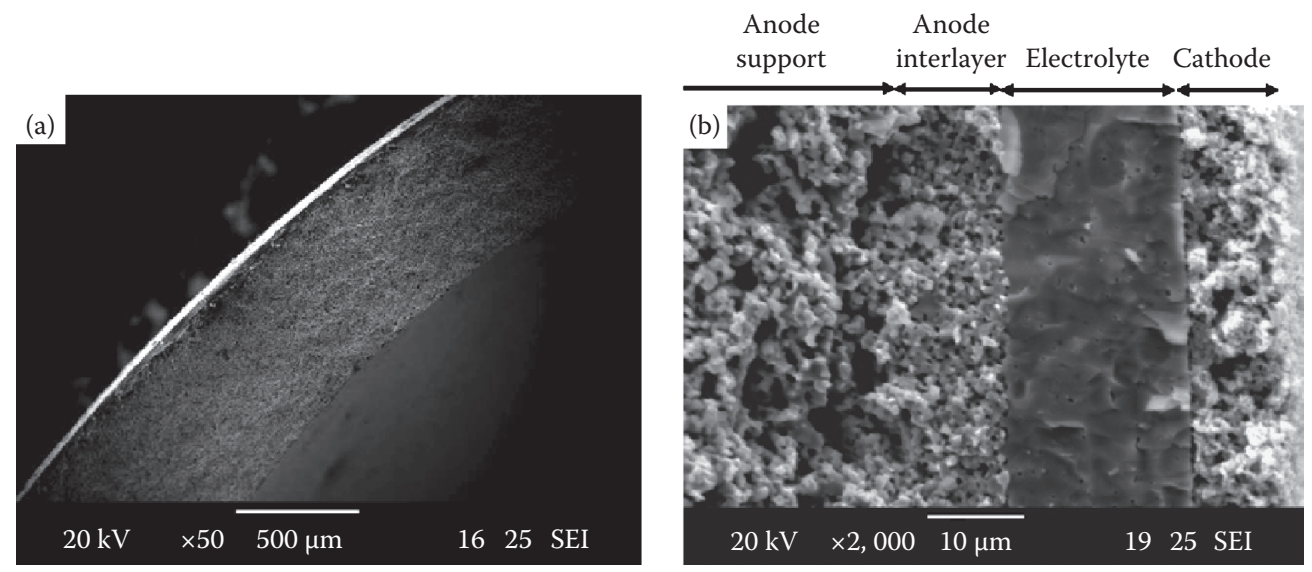

FIGURE 5.14 SEM micrographs of (a) an overview of the tubular cell and (b) the cross section of the tubular cell after testing, showing the thin YSZ electrolyte film and multilayer cathode prepared by dip-coating method. (From Zhang, L. et al., J. Am. Ceram. Soc., 92, 302, 2009.) 
anode supports and multilayer cathode, the cell achieved a peak power density of $1104 \mathrm{~mW} \mathrm{~cm}^{-2}$ in $\mathrm{H}_{2} /$ air and $770 \mathrm{~mW} \mathrm{~cm}^{-2}$ in $\mathrm{CH}_{4} /$ air at $800^{\circ} \mathrm{C}$. Dip-coating method was also used by Yamaguchi et al. [91] to deposit GDC electrolyte on extruded anode-supported microtubular cells.

Dip-coating technique is also applied to deposit YSZ or GDC electrolyte films as thin as $\sim 100 \mathrm{~nm}$ [92]. In this case, it is important to control the quality of the microstructure of the substrate as well as the YSZ and GDC sol containing nanoparticles $(5-6 \mathrm{~nm})$. For example, nano-structured zirconia sol can be produced by controlled hydrolysis of $\mathrm{Zr}\left(\mathrm{n}-\mathrm{O}_{3} \mathrm{H}_{7}\right)_{4}$ and $\mathrm{Y}\left(\mathrm{i}-\mathrm{O}_{3} \mathrm{H}_{7}\right)_{3}$ in the presence of diethanol amine (DEA) as precursor modifier/polymerization inhibitor. DEA acts as a drying controlling additive and is important for the formation of nanoparticles in the synthesis process. In conventional slurry- or dip-coating process, as many as 10 sequential dip-drying-calcination steps are required to obtain sufficiently thick and dense film. These repeated dip-coating-drying-calcination processes are time-consuming.

Wang et al. [93] showed that the composition of the dip-coating slurry has a significant influence on the quality of the YSZ thin films. Among the three commonly used composite solvents, trichloroethylene (TCE)/MEK, MEK/EtOH, and EtOH/TCE, YSZ suspension in MEK/EtOH solvents gave the best dispersibility and stability. Also $\mathrm{MEK} / \mathrm{EtOH}$ has an evaporation temperature of $74.8^{\circ} \mathrm{C}$, low enough for facilitating the formation of YSZ electrolyte thin films. Adding binder (PVB) and plasticizer (PEG and PHT) improves the stability. Thin and dense $16 \mu \mathrm{m}$ thick YSZ films were prepared by dip coating twice, and the cell with $\mathrm{NiO} / \mathrm{YSZ}$ anode and $\mathrm{Pt}$ cathode reached a power density of $262 \mathrm{~mW} \mathrm{~cm}{ }^{-2}$ at $800^{\circ} \mathrm{C}$. Rather than dip-coating, Liu et al. [94] drop-coated a YSZ suspension on porous electrode support to forming a thin and dense dual SDC-YSZ electrolyte films. Zhang et al. [95] showed that slurry casting could also be used to deposit thin YSZ electrolyte film on a NiO/YSZ substrate disc assisted by a revolving rod to spread and compact the YSZ layer. However, the revolving or rotating-assisted slurry-casting technique would be difficult to scale up for the fabrication of large area planar cells.

Vacuum slip or slurry casting is used to deposit thin GDC electrolyte layer on LSCF/GDC composite cathode substrates [96]. In addition to the preparation of YSZ electrolyte layer, slurry coating or slurry spray is also used for the deposition of anode and cathode interlayers [97]. The results show that the inclusion of electrode interlayers significantly improved the performance of the anode-supported cells and the reasons for the improvement could be related to the introduction of a diffuse mixed conduction region associated with the interlayers. However, slurry or slip-casting is commonly used to fabricate thick NiO/YSZ anode substrates or tubes for anode-supported thin electrolyte SOFCs.

\subsubsection{Sol-Gel Method}

In sol-gel methods, organometallic salts, such as metal alkoxides (e.g., zirconium propoxide and yttrium propoxide), are deposited on porous electrode substrates and hydrolyzed under controlled conditions, forming a colloidal sol and a condensation step with organic monomers to form a gel. The deposition by methods such as by spin coating or dip coating is followed by a drying and firing process, leading to the formation of a dense electrolyte film. The key feature in this sequence is solgel polymerization, which can be described by a two-step reaction: initiation via the hydrolysis of alkoxy ligands and polycondensation via an oxylation reaction. The particle concentration, viscosity, concentration, and stability of the sol-gel influence the deposition parameters and film quality and have to be controlled carefully. The nature of the porous substrate is also critical in the sol-gel processes. Large pores could lead to pore-induced defects. Thus the substrate should have a porosity that is both submicron and uniform. Dunn et al. [98] gave an overview and briefly discussed the sol-gel chemistry.

Mehta et al. [99] used sol-gel method to deposit a thin (100-300 nm) YSZ layer on yttrium-doped ceria (YDC) electrolyte to block the electron transfer. An ethyl alcohol solution of YSZ was made by dissolving $11 \mathrm{~mol} \%$ yttrium isopropoxide and $89 \mathrm{~mol} \%$ zirconium isopropoxide in anhydrous isopropanol. The solvent was slightly heated and a small amount of $\mathrm{HNO}_{3}$ was added to promote 
dissolution and hydrolysis. The YSZ precursor solution was applied to a YDC electrolyte substrate by spin coating. Formation of the cubic YSZ phase was achieved at $600^{\circ} \mathrm{C}$ in air. A $0.25 \mathrm{M}$ solution used in spin coating results in a $\sim 100 \mathrm{~nm}$ thick YSZ layer after heat treatment. The open circuit voltage (OCV) of the two-layer YSZ-YDC electrolyte cell is increased by $150-200 \mathrm{mV}$ as compared to an uncoated YDC electrolyte cell in the temperature range of $600^{\circ} \mathrm{C}-800^{\circ} \mathrm{C}$ in $\mathrm{H}_{2} / \mathrm{O}_{2}$. The compatibility of the two-layer YSZ-YDC electrolyte cell was also studied by Kim et al. [79] using a sol-gel spin coating method. The YSZ film deposited by sol-gel spin coating method showed a crack- and pinhole-free microstructure after sintered at $1400^{\circ} \mathrm{C}$. A $2 \mu \mathrm{m}$ thick YSZ film on YDC electrolyte can be obtained after six repetitive spin coatings. However, the maximum power density of the twolayer cell is comparable to a YSZ single layer cell with the same thickness at $1000^{\circ} \mathrm{C}$.

Lee et al. [100] used sol-gel dip-coating method to deposit a lanthanum chromite-based perovskite coating on a ferritic stainless steel (SUS444) to reduce the oxidation rate of the metallic interconnect. Precursor solutions for $(\mathrm{La}, \mathrm{Ca}) \mathrm{CrO}_{3}(\mathrm{LCCr})$ and $\mathrm{LSCr}$ coatings were prepared by adding nitric acid and ethylene glycol into an aqueous solution of lanthanum, strontium (or calcium), and chromium nitrates. Dried LCCr and LSCr gel films were heat treated at $400^{\circ} \mathrm{C}-800^{\circ} \mathrm{C}$ after dip coating on the SUS444 substrate. The SEM results show that the microstructure of LCCr film is denser than that of LSCr. The porous structure of LSCr layer is attributed to the formation of the $\mathrm{SrCrO}_{4}$ phase. The presence of LCCr and LSCr thin-film layers depress the oxidation of the SUS444 metallic substrate.

The sol-gel method possesses the advantages of precise composition control, simple processing procedure, and low processing temperatures. However, thin films based on the sol-gel process also have several demerits. For example, a large shrinkage during heat treatment and low density from inherent high organic content may cause local defects, resulting in serious gas leakage and crossover.

\subsubsection{Screen-Printing Method}

In the screen-printing process, a highly viscous paste consisting of a mixture of ceramic powder, organic binder, and plasticizer is forced through the open meshes of a screen using a squeegee. The screen-printed films are dried and sintered at high temperatures. Parameters such as grain size, grain form, slurry viscosity, and sintering temperature and time are important for the quality and densification of the screen-printed film. Slip casting and screen-printing usually involve large shrinkage associated with the removal of polymeric binders and plasticizers in subsequent sintering and heat treatment stages. This would deteriorate the quality of the thin films.

Zhang et al. [101] used screen-printing technique to fabricate $\mathrm{Sm}_{0.2} \mathrm{Ce}_{0.8} \mathrm{O}_{2}$ (SDC, $\left.15 \mu \mathrm{m}\right)$ single layer and YSZ $(5 \mu \mathrm{m})+\mathrm{SDC}(15 \mu \mathrm{m})$ bilayer on Ni/YSZ cermet substrate, followed by co-firing. Co-firing at $1400^{\circ} \mathrm{C}$ led to the formation of $\mathrm{Zr}$-rich micro-islands, indicating the $\mathrm{Zr}$ migration from the $\mathrm{NiO} / \mathrm{YSZ}$ substrate during the co-firing process. Screen-printing was used to deposit $\mathrm{Sm}_{0.2} \mathrm{Ce}_{0.8} \mathrm{O}_{2}$ (SDC) electrolyte thin film onto the green $\mathrm{NiO} / \mathrm{SDC}$ anode substrates using a printing slurry consisted of SDC powder, methylcellulose, terpineol, and ethanol vehicle [102]. A dense SDC electrolyte layer with thickness of $\sim 30 \mu \mathrm{m}$ was obtained after co-firing at $1350^{\circ} \mathrm{C}$ in air for $5 \mathrm{~h}$. The cell with SSC cathode, Ni/GDC anode, and screen-printed SDC electrolyte achieved a power output of $397 \mathrm{~mW} \mathrm{~cm}^{-2}$ in $\mathrm{H}_{2}$ and $304 \mathrm{~mW} \mathrm{~cm}^{-2}$ in methane at $600^{\circ} \mathrm{C}$, an impressive performance at these low temperatures.

Joo and Choi [103] fabricated $\mu$-SOFCs based on a porous and thin Ni substrate using the screenprinting technique. Figure 5.15 shows the fabrication process for $\mu$-SOFCs using screen-printing techniques. The $\mathrm{NiO}$ ink was made of commercial $\mathrm{NiO}$ powder mixed with an organic solution of $\alpha$-terpineol and ethyl cellulose in a weight ratio of 10:1. A phosphate ester-based surfactant and dihydroterpineol acetate were used as dispersants. The Ni film was fabricated by screen-printing a $\mathrm{NiO}$ film on a ceramic substrate and subsequently reducing the printed film at $700^{\circ} \mathrm{C}-750^{\circ} \mathrm{C}$ in hydrogen. After reduction, a freestanding and porous Ni film was obtained. A thin GDC electrolyte film $(\sim 3 \mu \mathrm{m})$ was deposited on Ni substrate by the PLD method at an oxygen partial pressure 
1. $\mathrm{NiO}$ paste prepared by mixing $\mathrm{NiO}$ powder with organic solution and three-roll milled.

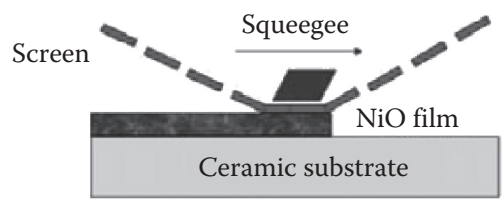

2. $\mathrm{NiO}$ paste screen-printed the ceramic substrate.

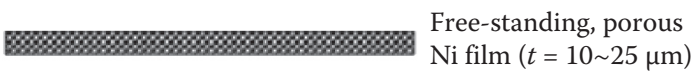

3. $\mathrm{NiO}$ film reduced in $\mathrm{H}_{2}$ atmosphere at $700^{\circ} \mathrm{C} \sim 750^{\circ} \mathrm{C}$ and removed from substrate.

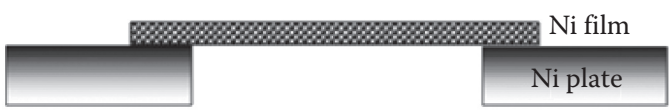

4. Porous Ni film attached to dense Ni plate.

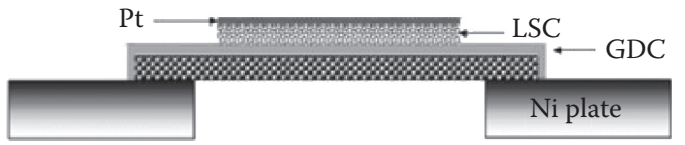

5. GDC, LSC, and Pt films deposited sequentially on porous Ni support.

FIGURE 5.15 Fabrication process for $\mu$-SOFC based on a screen-printed porous Ni substrate. (From Joo, J.H. and Choi, G.M., J. Power Sources, 182, 589, 2008.)

of $\sim 30 \mathrm{~mm}$ torr, followed by the deposition of a porous LSCo cathode for $90 \mathrm{~min}$ at room temperature. The deposition at room temperature produces the porous structure of LSC as required for the cathode. The cell achieved a maximum power output of $26 \mathrm{~mW} \mathrm{~cm}^{-2}$ at $450^{\circ} \mathrm{C}$ in $\mathrm{H}_{2} /$ air. The advantage of the screen-printing is its simplicity and low cost particularly in comparison to the lithography and etching processes commonly used in the fabrication of $\mu$-SOFCs.

\subsubsection{Electrophoretic Deposition}

Electrophoretic deposition (EPD) is one of the colloidal processes by which ceramic films are shaped directly onto substrates from an electrostatically stabilized colloidal suspension in a DC electrical field. A DC electrical field causes these charged particles to move forward, and deposit on an electrode with opposite charge. The EPD process has been used for the fabrication of SOFC components including YSZ [104,105], and $(\mathrm{La}, \mathrm{Sr})(\mathrm{Ga}, \mathrm{Mg}) \mathrm{O}_{3}$ electrolyte films [106,107]. The EPD process is very simple and has the advantage of uniformity of deposition and high deposition rates. In the case of deposition of YSZ thin electrolyte layers, YSZ nanoparticles are dispersed in an organic suspension medium, such as ethanol, acetylacetone, or iodine-dissolved acetylacetone, instead of water, to avoid the detrimental effect of water electrolysis on the quality of deposited film. Positive charges are developed on the YSZ particles due to the presence of some residual water. A solid concentration of $10 \mathrm{~g} \mathrm{~L}^{-1}$ was found to be suitable for EPD using acetylacetone as solvent [108]. Iodine-dissolved acetylacetone is an effective solvent for EPD as it has a much lower resistance than ethanol [104,109]. Lower solution resistance reduces the applied voltage, depressing evolution of gases on the negative (i.e., deposited) electrode. Dispersion of YSZ in an iodine $\left(\mathrm{I}_{2}\right)$-acetone solution is effective to form charged YSZ particles as the reaction between acetone and iodine produces protons that are absorbed by the YSZ particles; subsequently, the YSZ particles become positively charged by the addition of $\mathrm{I}_{2}[110]$. 
EPD process can be generally characterized by two steps [111]. Under the application of an electric field, the charged particles first migrate toward an electrode with opposite charge. The migration depends on the bulk properties of the colloidal dispersion (bath conductivity, viscosity, particle concentration, size distribution, and surface charge density) and the actual field strength in the bath. The charged particles coagulate at or near the surface of the deposited electrode, forming a solid deposit layer. A suitable heat treatment (firing or sintering) is usually required in order to further densify the deposited film and to eliminate porosity. For a detailed discussion and application of the EPD process, readers are encouraged to read an excellent review by Besra and Liu [112].

A prerequisite for EPD is that the substrate should be electrically conductive. Thus, for deposition of YSZ or GDC electrolyte thin films on nonconducting NiO/YSZ anode supports, thin conducting layers such as graphite and $\mathrm{Pt}$ are coated onto the porous NiO/YSZ composite substrates to facilitate conduction on the surface. For the deposition of YSZ thin films onto porous NiO/YSZ composite substrates that have been pre-coated with graphite thin layers, YSZ layer can be deposited onto the substrates or onto the graphite layers on the substrates, as shown in Figure 5.16 [113]. Figure 5.17 shows the SEM micrographs of the cross section for YSZ films electrophoretically deposited onto $\mathrm{NiO} / \mathrm{YSZ}$ substrate surface [113]. For YSZ powders deposited onto porous $\mathrm{NiO} / \mathrm{YSZ}$

(a)

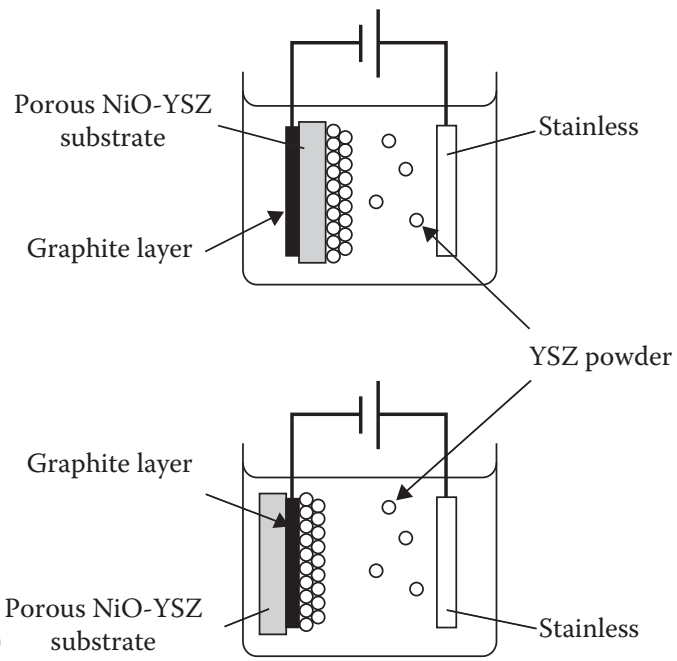

FIGURE 5.16 Experimental setup for (a) EPD of YSZ powders onto porous NiO/YSZ substrates whose reverse side is coated with conducting graphite layers and (b) EPD of YSZ powder onto conducting graphite layers on $\mathrm{NiO}$ /YSZ substrates after co-firing. (From Hosomi, T. et al., J. Eur. Ceram. Soc., 27, 173, 2007.)

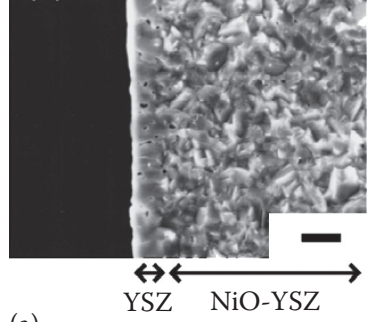

(a)

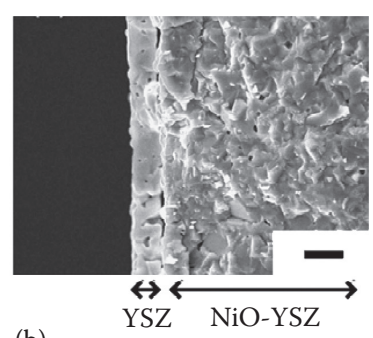

(b)

FIGURE 5.17 SEM micrographs of cross-section EPD of YSZ thin films electrophoretically deposited onto porous $\mathrm{NiO} / \mathrm{YSZ}$ substrates whose reverse side is coated with conducting graphite layers (a) and onto conducting graphite layers on NiO/YSZ substrates (b). (From Hosomi, T. et al., J. Eur. Ceram. Soc., 27, 173, 2007.) 
substrates whose reverse side is coated with conducting graphite layers, the YSZ powders are subsequently transferred into dense and continuous films with thickness of 3-15 $\mu \mathrm{m}$ after co-firing with substrates (left picture, Figure 5.17). For the YSZ films deposited onto graphite layer, an opening is observed at the interface after co-firing (right picture, Figure 5.17), most likely due to the burning and decomposition of the graphite interlayer.

Besra et al. found that in the case of EPD of YSZ thin layers on nonconducting NiO/YSZ substrates with carbon sheet backing, the deposition of YSZ increases with increasing substrate porosity, indicating the presence of a continuous "conducting path" between the electrical contact and the particles through pores in the substrate [108]. The results indicate a minimum threshold porosity of the $\mathrm{NiO} / \mathrm{YSZ}$ substrates, which is $52.5 \%$ and $58.5 \%$ porosity for 100 and $25 \mathrm{~V}$ applied potentials, respectively. Cherng et al. [114] showed that Ni/YSZ cermet presintered at $1200^{\circ} \mathrm{C}$ and reduced at $700^{\circ} \mathrm{C}$ behaves like a metal electrode and does not require the use of the additional electrical conducting backing layer.

Cherng et al. [114] studied the EPD of YSZ thin films using aqueous suspension. To prevent the colloids from agglomeration and sedimentation during EPD, negatively charged polyelectrolytes, such as ammonium polyacrylate (PAA- $\mathrm{NH}_{4}$ ), are added as dispersant. $\mathrm{PAA}-\mathrm{NH}_{4}$ dissociates in water, forming negatively charged polyanions that would adsorb to YSZ particles to stabilize them electrostatically. Addition of $\sim 0.1 \mathrm{wt} \%$ PAA- $\mathrm{NH}_{4}$ is sufficient to stabilize the YSZ slurry. The aqueous EPD is characterized by low current $\left(<3 \mathrm{~mA} \mathrm{~cm}^{-2}\right)$ and low voltage $(<20 \mathrm{~V})$ on conducting substrates. Will et al. [115] showed that through adjustment of shrinkage and the shrinkage rate of the deposited zirconia layer on the presintered porous Ni/YSZ substrate, thin, dense layers without cracks can be prepared. The thickness of the deposited YSZ layer could be monitored from the total charge transfer during the EPD process. EPD method was also used to deposit a NiO/YSZ anode and a YSZ bilayer structure with a good interface bonding between the anode and electrolyte [116], and to deposit YSZ on a porous LSM cathode substrate [105,110].

The EPD can be used for mass production and has the advantages of short formation times, little restriction in the shape of deposition substrates, suitability for mass production, and a simple deposition apparatus. In addition, there is no requirement of binder burnout because the green coating contains little or no organics. However, it has been shown that five or more successive repetitions of the process are necessary to produce a gastight and dense YSZ layer and to achieve a good cell performance $[104,105]$.

\subsubsection{Ceramic Powder Techniques}

\subsubsection{Tape-Casting and Freeze-Tape-Casting Process}

Tape casting is a commercial processing technology that has been used extensively for the manufacturing of electronic and structural ceramics with thicknesses typically ranging from 25 to $1000 \mu \mathrm{m}$ and is particularly suitable for making anode-supported planar SOFCs. Tape casting involves spreading of slurries of the ceramic powders and organic ingredients, such as the modifier, organic binders, dispersant (fish oil), and solvents (ethanol and toluene), onto a flat surface where solvents are allowed to evaporate. After drying, the resulting tape develops a leather-like consistency and can be stripped off from the casting surface; see Figure 5.18. To increase the porosity of the anode supports, graphite or other pore formers can be added.

Typically, tape-cast anode layer ( $1-2 \mathrm{~mm}$ thick) and tape-cast electrolyte layer (40-100 $\mu \mathrm{m}$ thick) are produced and these two tapes are laminated and after rolling or calendering, the green laminates are cut to size and sintered at $1300^{\circ} \mathrm{C}-1400^{\circ} \mathrm{C}$ in a specially designed kiln furnace to ensure the parts are all flat. The final anode-supported structures are produced with an anode support thicknesses of $500-1000 \mu \mathrm{m}$ and electrolyte thicknesses of $15-40 \mu \mathrm{m}$. Tape-casting technique is also used to produce thick electrolyte of $\sim 100 \mu \mathrm{m}$ for electrolyte-supported cells. Figure 5.19 shows typical structure of YSZ electrolyte-supported and Ni/YSZ cermet anode-supported thin YSZ cells. Mismatch in densification of such bilayer structures will cause intolerable bending and/or cracking 


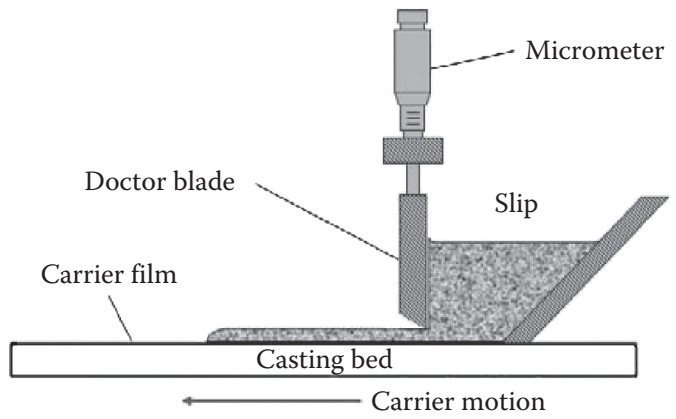

FIGURE 5.18 Typical tape-casting apparatus.

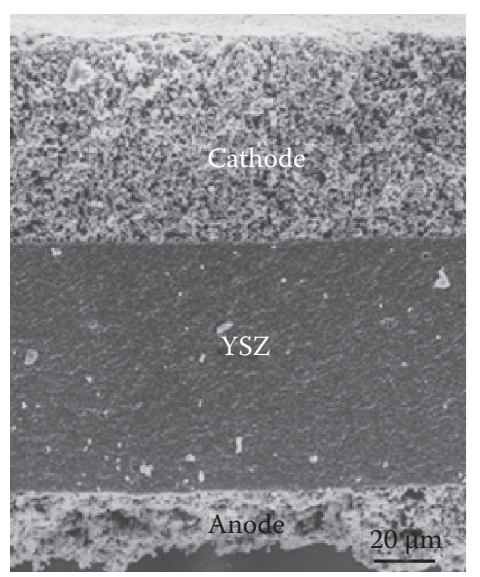

(a)

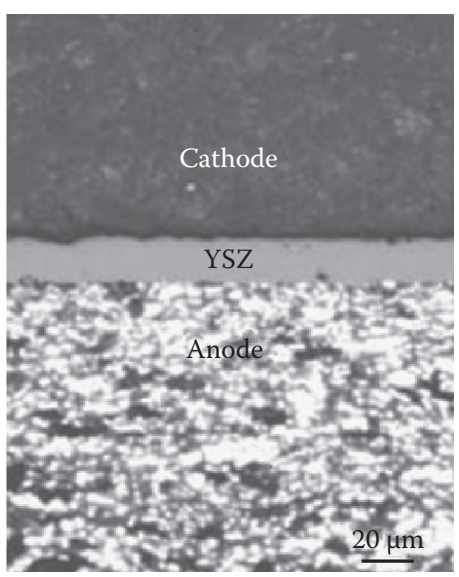

(b)

FIGURE 5.19 (a) YSZ electrolyte-supported cell and (b) Ni/YSZ anode-supported cells prepared by tapecasting technique.

of the structure during co-firing [117]. Thus, match in the sintering profile of the laminated anode and electrolyte tapes is critical in producing flat anode-supported structures.

Tape casting is also used to prepare porous anode substrate for anode-supported thin electrolyte cells. Park et al. [118] reported the fabrication of anode-supported thin electrolyte SOFCs by using two tape-casting layers of YSZ, one containing a pore former as a porous YSZ anode matrix and one without pore former as the electrolyte layer. The porosity of the anode tape was controlled by the addition of pore formers. Addition of $30 \%$ pore former resulted in the formation of $\sim 50 \%$ porosity for the YSZ anode substrate tape. The shape of pores in the porous YSZ matrix is related to the shape of the pore formers that are used. After the formation of the composite structure at $1550^{\circ} \mathrm{C}$, copper and ceria were added to the porous YSZ layer by wet impregnation. However, the ability to engineer pore structures is limited to the manipulation of thermal fugitive particle orientation and stability during the slurry process.

A combination of the tape-casting process and freeze-casting process has resulted in a new freeze-tape-casting process that has been developed as a direct means of forming and controlling complex pore structures in green tapes. The freeze-tape-casting process not only allows tailoring of continuously graded pores through the entire cross section but also slows for long-range alignment of acicular pores from the surface. The freeze-tape-casting process starts with the traditional tape-casting process, where an aqueous ceramic slip is cast onto a Mylar or Teflon carrier film via a doctor blade apparatus. A standard tape caster that has been modified only with a thermally isolated freezing bed to allow for unidirectional solidification of the slurry after casting is used. As 

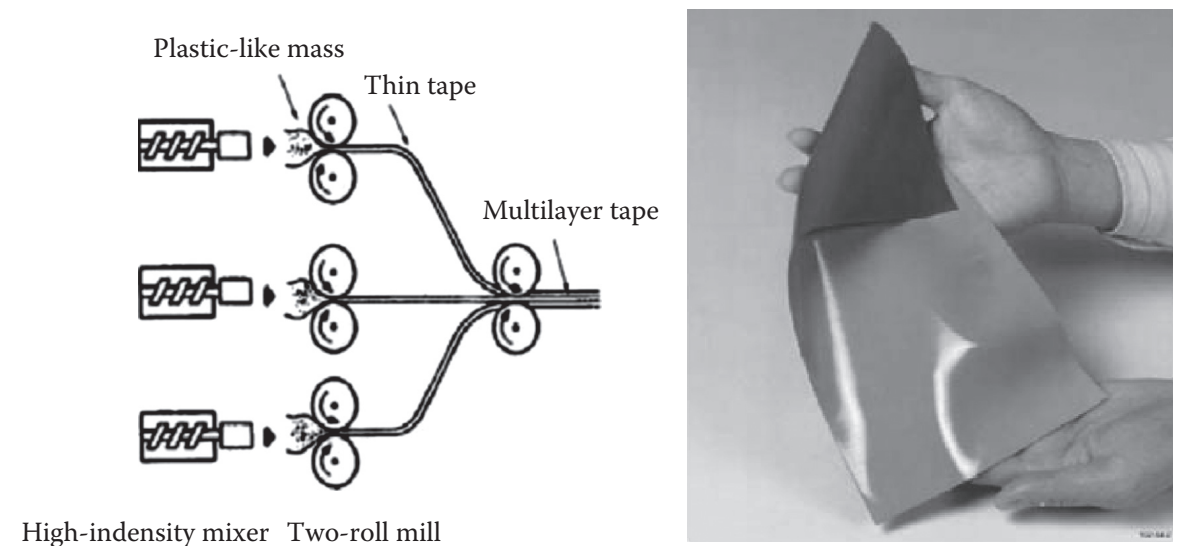

FIGURE 5.20 Tape-calendering process and green electrolyte/anode bilayer. (From Minh, N.Q., Solid State Ionics, 174, 271, 2004.)

with traditional tape casting, the slip contains sufficient organic binders that make the tape strong and flexible after solvent evaporation for handling and cutting. The freezing of the tape, typically solidified in several minutes, eliminates particles settling out of the suspension. After the solidification process, the tape is subsequently cut and freeze dried under a vacuum for quick solvent removal through sublimation, where the frozen liquid transforms from a solid to a gas without an intermediate liquid phase. Sofie [119] investigated in detail the fabrication of functionally graded and continuously aligned porous YSZ tapes $(500-1000 \mu \mathrm{m})$ by a modified freeze-tape-casting process using aqueous and tertiary butyl alcohol (TBA) solvents. The result indicates that the freeze-tape-casting technology can be effective in fabricating fuel cell components.

\subsubsection{Tape-Calendering Process}

The tape-calendering process for making thin-film SOFCs is based on the progressive rolling of green (unfired) ceramic tapes to produce a thin electrolyte film (typically $0.5-10 \mu \mathrm{m}$ ) on an electrode support [120,121]. The tape-calendering process (using an anode as the support) and green electrolyte/anode bilayer are shown in Figure 5.20 [122]. In this fabrication process, electrolyte and anode powders are first mixed with organic binders to form ceramic masses. The masses, having a doughy consistency with many of the characteristics of a plastic, are rolled into tapes using a tworoll mill. Electrolyte and anode tapes of certain thickness ratios are laminated and rolled into a bilayer tape. This thin bilayer is then laminated with a thick anode tape, and the lamination is rolled again into a thin bilayer tape. The process can be repeated with different tape thickness ratios until a desired electrolyte film thickness is obtained. In general, the process requires only three rollings to achieve a bilayer with micrometer-thick electrolyte films. The bilayer is fired at elevated temperatures to remove the binders and sinter the ceramics. To form a thin-film SOFC single cell, a cathode layer is applied on the electrolyte surface of the sintered bilayer. The process is simple and scalable. Cell size as large as $500 \mathrm{~cm}^{2}$ can be fabricated by this method.

\subsubsection{Dry-Pressing Method}

Xia and Liu developed a simple and cost-effective method to fabricate a thin GDC electrolyte film on $\mathrm{NiO} / \mathrm{GDC}$ anode substrates by dry pressing [123-125]. In this method, the green NiO/GDC substrate was formed by uniaxial pressing of NiO/GDC powder under $200 \mathrm{MPa}$. Highly porous or "foam" GDC powder, synthesized by a glycine nitrate combustion process, was carefully spread on top of the prepressed $\mathrm{NiO} / \mathrm{GDC}$ substrate, and then compressed at $250 \mathrm{MPa}$, forming a bilayer structure. Co-firing of the bilayer structure at $1350^{\circ} \mathrm{C}$ for $5 \mathrm{~h}$ yields a dense GDC membrane on a porous NiO/GDC electrode substrate. Care must be taken to ensure the uniform distribution of the 


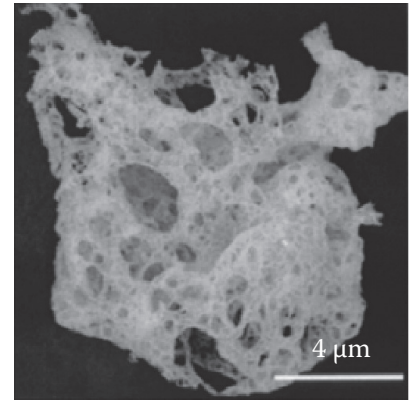

(a)

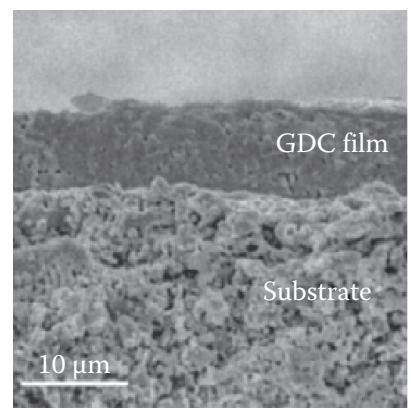

(c)

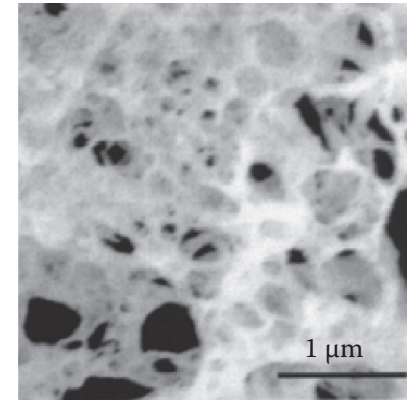

(b)

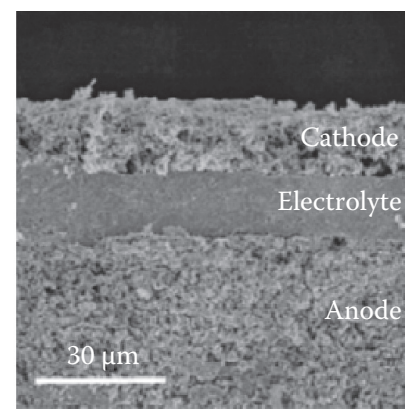

(d)

FIGURE 5.21 SEM micrographs of (a) a highly porous and foam-like GDC particle, (b) a portion of the particle shown in (a), (c) cross section of an $8 \mu \mathrm{m}$ thick GDC film on a NiO/GDC substrate, and (d) a fuel cell consisting of a $15 \mu \mathrm{m}$ thick GDC electrolyte, a Ni/GDC anode, and an $\mathrm{Sm}_{0.5} \mathrm{Sr}_{0.5} \mathrm{CoO}_{3}$ cathode. (From Xia, C.R. and Liu, M.L., J. Am. Ceram. Soc., 84, 1903, 2001.)

GDC powder on the substrate. Figure 5.21 are SEM micrographs of the as-synthesized GDC powder and the cross sections of a fuel cell consisting of thin GDC electrolyte layer prepared by dry pressing [123]. The GDC powder is highly porous; see Figure 5.21a and b. The relative density of the GDC foam powder is $0.84 \%\left(\sim 0.06 \mathrm{~g} \mathrm{~cm}^{-3}\right)$, based on the theoretical density of GDC $\left(7.12 \mathrm{~g} \mathrm{~cm}^{-3}\right)$. Low relative density indicates the low fill density of the powder. It is suggested that the extremely low fill density of the foam-like GDC is critical for the successful preparation of a thin, dense GDC electrolyte on a porous NiO/GDC substrate. The thickness of the GDC electrolyte is controlled by the amount of GDC powder.

The Gd-doped ceria electrolyte on anode substrates can also be formed in situ by solid-state reaction by dry pressing the stoichiometric $\mathrm{Gd}_{2} \mathrm{O}_{3}$ and $\mathrm{CeO}_{2}$ oxides [126]. The XRD analysis indicates that a single solid solution of $\mathrm{Gd}$-doped $\mathrm{CeO}_{2}$ is formed after sintering at $1450^{\circ} \mathrm{C}$. A maximum power density of $0.58 \mathrm{~mW} \mathrm{~cm}{ }^{-2}$ at $600^{\circ} \mathrm{C}$ was obtained on a $10 \mu \mathrm{m}$ thick GDC film and a LSCF/ GDC composite cathode. The dry pressing technique is simple and cost-effective. However, formation of a uniform and thin electrolyte film requires experience and skill particularly for the powder with high fill density. The scale-up of the dry pressing process may also be a problem due to the nature of the manual handing process.

\subsection{FLAME-ASSISTED COLLOIDAL PROCESS}

\subsubsection{Spray Pyrolysis and Flame-Assisted Vapor Deposition}

Figure 5.22 shows schematically a typical spray pyrolysis setup. A sufficient force, e.g., using a stream of gas at high speed, applied to the surface of a metal salt precursor solution (usually aqueous or alcoholic) or colloidal suspension in the atomizer/nozzle causes the emission of droplets. The 


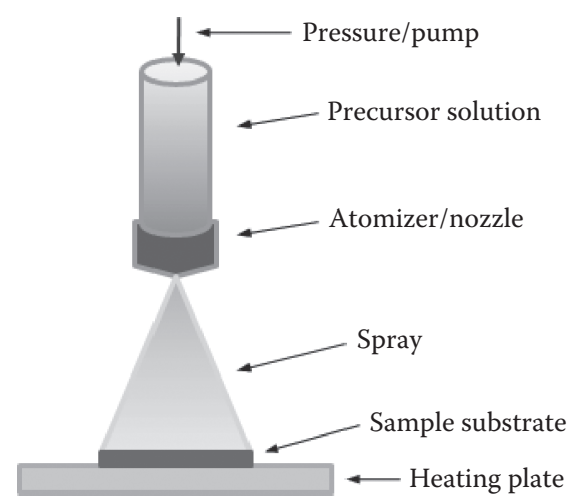

FIGURE 5.22 A schematic diagram of a typical spray pyrolysis setup.

solution can also be forced through the nozzle with a syringe pump. Sprayed droplets reaching the substrate surface undergo pyrolytic decomposition. Newly deposited flat droplets, with thickness in the 10-20 nm range, pile up on the previously deposited droplets and undergo pyrolytic decomposition as well. This process continues until a film thickness of $100-500 \mathrm{~nm}$ is reached [127]. The degree of decomposition is determined by the relationship between the substrate temperature, the boiling temperature of the solvents, and the melting point of the salts used for the precursor. A compromise has to be found between sufficiently high deposition temperature to achieve complete decomposition if possible and the facility to deposit the droplets while still in a wet state on the substrate for a piling up of the droplets. The spray pyrolysis synthesis method has been used widely for the preparation of SOFC electrolyte thin films as well as porous electrode coatings. The spray pyrolysis method offers high film quality and low processing costs compared to other thin-film deposition techniques such as PLD and chemical or physical vapor deposition. The spray pyrolyzed thin films are usually amorphous after deposition [128], which can be converted to a nanocrystalline isotropic microstructure with grain boundaries perpendicular to the film surface [129].

Rupp et al. [130] performed a comprehensive characterization of a $\mathrm{Gd}_{0.2} \mathrm{Ce}_{0.8} \mathrm{O}_{1.9-x}$ (GDC) thin film deposited by spray pyrolysis technique at $350^{\circ} \mathrm{C}$ and annealed at $1000^{\circ} \mathrm{C}$. The film composition was $\mathrm{Gd}_{0.23} \mathrm{Ce}_{0.77} \mathrm{O}_{1.9-x}$, slightly different from the ratio of the components in the precursor. The results also show that the pyrolysis process would lead to thin films that contain trace amounts of carbon and hydroxyl groups from the precursors. However, the residues of the spray pyrolysis film appear to have little effect on the electrical properties of the GDC films. The cracks formed during the thermal decomposition and heat treatment could be eliminated by optimizing the substrate temperature and repeating the film deposition and heating cycle [131].

Spray pyrolysis was also used to deposit porous and catalytic active NiO/SDC composite anode films at a substrate temperature $350^{\circ} \mathrm{C}$ and an annealing temperature $500^{\circ} \mathrm{C}$ [132]. Using a precursor sol consisting of solution prepared from strontium acetate, lanthanum nitrate and manganese nitrate dissolved in propane-1,2-diol and LSM powder at a concentration of $0.2 \mathrm{~mL}^{-1}$, a thin porous LSM electrode with distribution of pores between 2 and $3 \mu \mathrm{m}$ has been deposited by spray pyrolysis [133]. Porous coatings can also be obtained by powder spray without subsequent decomposition at the substrate (i.e., wet powder spraying). However, the adhesion and uniformity of the porous coating would be difficult to be controlled.

Flame assisted vapor deposition (FAVD) is a combination of spray pyrolysis and flame synthesis. In this method, an atomized solution is sprayed through a flame in an open atmosphere in which decomposition and combustion reactions occur, resulting in a stable film deposited on a heated substrate. This method requires simple apparatus and is performed at a relatively low temperature and at a high deposition rate. Choy et al. [134] prepared porous LSM cathodes by FAVD. Ethanol is added to the nitrite precursor solution to make the solution more inflammable. The morphology 
and porosity of the LSM coating depend strongly on the deposition temperature (i.e., the substrate temperature). A LSM electrode deposited at a deposition temperature of $710^{\circ} \mathrm{C}$ produced a rather high polarization resistance of $1.34 \Omega \mathrm{cm}^{2}$ at $900^{\circ} \mathrm{C}$. FAVD was also used to fabricate multilayer LSM/doped $\mathrm{CeO}_{2}$ on YSZ electrolyte [135].

Similar to FAVD, combustion CVD (CCVD) is an open-air, flame-assisted chemical deposition process, capable of producing a wide range of coating morphologies from very dense to highly porous structures. Liu et al. [136] successfully employed CCVD to fabricate functionally graded LSM/LSC/GDC cathodes on YSZ electrolyte using nitrate solution precursors. In this method, methane is used as the fuel gas and oxygen as the oxidant for the combustion flame. Grain sizes as small as $\sim 50 \mathrm{~nm}$ can be obtained.

The spray pyrolysis deposition has the advantages of simple set-up, inexpensive and nontoxic precursors, high deposition efficiency, and direct deposition under ambient atmosphere.

\subsubsection{Electrostatic Spray Deposition}

Spray pyrolysis of aerosol under electrostatic field, electrostatic spray pyrolysis deposition or electrostatic spray deposition (ESD), has been developed and used to prepare thin electrolyte and electrode layers for SOFCs [137]. In the case of ESD, a high DC voltage (e.g., 6-10kV) is applied between the nozzle (positive polarity) and the grounded substrate (negative polarity) of a normal spray pyrolysis device of Figure 5.22. The distance between the nozzle and the grounded substrate is in the range of $30-50 \mathrm{~mm}$. ESD makes use of electrostatic charging to disperse the liquid. The advantage of electrostatic dispersion is that the unipolar (usually positive) charge helps to achieve very small drop sizes. The charge also prevents coalescence of drops, hence agglomeration of particles, during spray. Also, the electric field allows a high degree of control over the direction of flight and the distribution of the rate of deposition over the substrate. For fundamental aspects of the ESD or electrospraying techniques in general, readers should refer to a detailed review by Jaworek [138].

Nomura et al. [139] studied the effect of ESD process on the morphology and density of thin YSZ layers on Ni/YSZ anode substrates using a colloidal suspension of YSZ. Direct use of colloidal suspension would avoid the chemical reactions associated with the precursor solutions during the dispersion and deposition process. Operating parameters such as colloidal concentration, particle size of feed solution, solution medium, flow rate, nozzle tip shape, distance between nozzle and substrate, substrate temperature, and applied voltage were found to be important on the quality and morphology of the deposited YSZ films. For example, the shape of the nozzle tip strongly affects the type of spray. A thin-layer ( $\sim 3 \mu \mathrm{m}$ thickness) YSZ electrolyte was deposited on Ni/YSZ anode substrate, achieving an open circuit of $1.06 \mathrm{~V}$ at $800^{\circ} \mathrm{C}$.

Fu et al. [137] used ESD to deposit porous LSCF films on stainless steel and glass substrates using metal nitrate precursor solutions. The as-deposited films are amorphous, but after calcining at $750^{\circ} \mathrm{C}$, the deposited films crystallize to form the perovskite phase. Films obtained at the deposition temperature of $350^{\circ} \mathrm{C}$ are much more porous than those obtained at $150^{\circ} \mathrm{C}$ and $250^{\circ} \mathrm{C}$, which is attributed due to the preferential landing of aerosol droplets and agglomeration of particles. Princivalle and Djurado [140] studied the effect of YSZ content and nozzle-to-substrate distance on the morphology of LSM/YSZ composite cathodes on YSZ substrate by ESD. Shown in Figure 5.23 are SEM micrographs of the LSM/YSZ composite films deposited at $350^{\circ} \mathrm{C}$ as a function of YSZ content in the composites [140]. The nozzle-to-substrate distance was $45 \mathrm{~mm}$. When the YSZ content in the composites was lower than $50 \mathrm{wt} \%$, the deposited composite film morphology was found reticulate and highly porous; see Figure 5.23a-c. In the case of 40\% LSM/60\% YSZ composite coatings, the ESD LSM/YSZ coating becomes much denser; see Figure 5.23d. The simultaneous boiling and drying of the solution with low YSZ content is suggested to be the origin of the formation of reticulate coatings. ESD was also used to deposit highly porous LSCF thin layers on SDC electrolyte before applying the screen-printed LSCF cathode [141]. The LSCF double layer cathode reduces the electrode polarization resistance by $50 \%$ as compared to single layered LSCF cathode. 


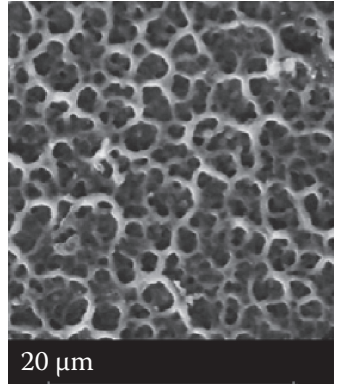

(a)

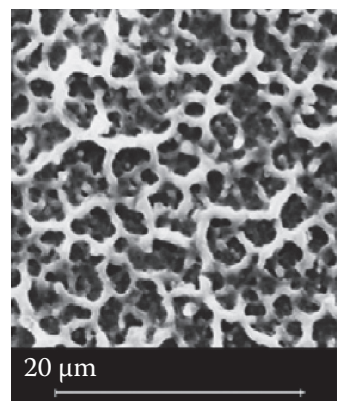

(c)

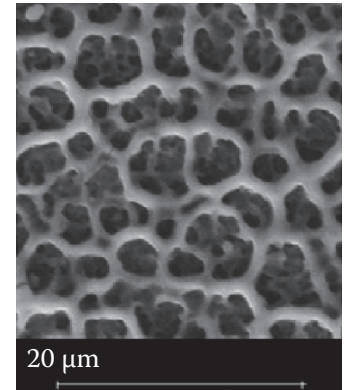

(b)

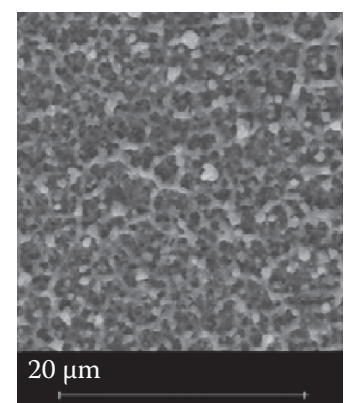

(d)

FIGURE 5.23 SEM micrographs of the LSM/YSZ composite films deposited at $350^{\circ} \mathrm{C}$ for YSZ content of (a) $21 \%$, (b) $43 \%$, (c) $50 \%$, and (d) $60 \%$ in the composites. (From Princivalle, A. and Djurado, E., Solid State Ionics, 179, 1921, 2008.)

\subsection{LITHOGRAPHY AND ETCHING TECHNIQUES FOR $\mu$-SOFCS}

Lithography in combination with an etching process based on substrates such as Ni or silicon wafers has been used in the design and fabrication of miniature or $\mu$-SOFCs. Chen et al. [142] fabricated a micro thin-film SOFC based on thin-film deposition and microlithographic processes. The $\mu$-SOFC is composed of a thin-film electrolyte deposited on a nickel foil substrate by PLD. The Ni foil substrate was then processed into a porous anode by photolithographic patterning and wet etching to develop pores for gas transport into the fuel cell. $\mathrm{A} \mathrm{La}_{0.5} \mathrm{Sr}_{0.5} \mathrm{CoO}_{3}$ thin-film cathode was then deposited on the electrolyte, and a porous $\mathrm{NiO} / \mathrm{YSZ}$ cermet layer was added to the anode to improve the electrode performance. The $\mu$-SOFC yielded a maximum output power density of $110 \mathrm{~mW} \mathrm{~cm}^{-2}$ at $570^{\circ} \mathrm{C}$. Huang et al. [37] fabricated a thin-film SOFC containing 50-150 nm thick YSZ or GDC electrolyte and $80 \mathrm{~nm}$ porous $\mathrm{Pt}$ cathode and anode, using sputtering, lithography, and etching techniques. The peak power densities are 200 and $400 \mathrm{~mW} \mathrm{~cm}^{-2}$ at $350^{\circ} \mathrm{C}$ and $400^{\circ} \mathrm{C}$, respectively. The high power densities achieved was attributed to the ultrathin electrolyte and the high charge-transfer reaction rates at the interfaces between the nanoporous electrodes (cathode and/or anode) and the nanocrystalline thin electrolyte. The unit cell area was $0.06 \mathrm{~mm}^{2}$ and increasing the cell area may be difficult due to the inadequate mechanical strength of the freestanding electrolyte films.

Prinz's group [22] fabricated freestanding ultrathin corrugated YSZ electrolyte cells using a sequence of MEMS processing steps. The SOFC is based on a corrugated thin-film electrolyte, which is generated by a pattern transfer technique. Figure 5.24 shows the process flow for fabrication of the corrugated thin-film $\mu$-SOFC. A $350 \mu \mathrm{m}$ thick, (100) n-type silicon wafer is used to generate the template. One side of the silicon surface is patterned by standard photolithography and deep reactive ion etching (DRIE) to create cup-shaped trenches with smooth cup sidewall surface. A $100 \mathrm{~nm}$ thick low stress silicon nitride is deposited on both sides of the wafer with low pressure chemical vapor deposition (LPCVD). On the opposite side to the etched trenches, the silicon nitride 
(a)

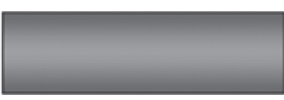

(b)

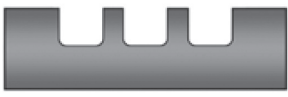

(c)

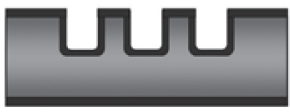

(d)

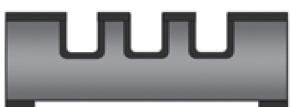

(e)

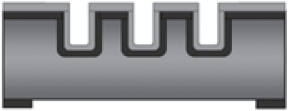

(f)

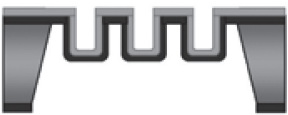

(g)

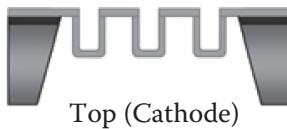

(h)

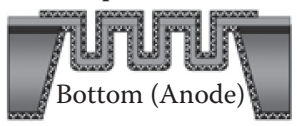

YSZ

Platinum

FIGURE 5.24 Process flow diagram for fabrication of the corrugated thin-film SOFC. The (100) silicon substrate is etched by DRIE to generate the template for pattern transfer (a, b). A $100 \mathrm{~nm}$ thick silicon nitride layer is deposited with LPCVD on both sides of wafer (c). The backside of silicon nitride is patterned with openings (d), followed by ALD deposition of YSZ onto template (e). Silicon template is etched in $\mathrm{KOH}$ (f) and silicon nitride etch stop is removed by plasma etching $(\mathrm{g})$. The freestanding corrugated electrolyte is deposited with porous platinum on top (cathode) and bottom (anode) sides acting as both electrode and catalyst. (From Su, P.C. et al., Nano Lett., 8, 2289, 2008. With permission.)

layer is patterned to generate square openings for subsequent silicon etching. ALD technique is applied to deposit the ultrathin YSZ electrolyte, forming a corrugated film ( $70 \mathrm{~nm}$ thick). To release the YSZ membrane, the silicon substrate is immersed into a $30 \mathrm{wt} \% \mathrm{KOH}$ solution for $5 \mathrm{~h}$ at $85^{\circ} \mathrm{C}$. $\mathrm{Pt}$ anode and cathode are then sputtered on both sides of the freestanding YSZ membrane to form the cell. The maximum power density is $677 \mathrm{~mW} \mathrm{~cm}^{-2}$ at $400^{\circ} \mathrm{C}$ [22].

However, photolithography, in combination with the etching process, is complicated and often difficult since the etching process could damage the fuel cell materials. In addition, the resolution of wet etching is generally limited to $\sim 10 \mu \mathrm{m}$. Dry etching would allow much finer patterns but is time-consuming for a multilayered Ni-based substrates.

\subsection{CONCLUDING REMARKS}

Many different techniques are available for thin-film deposition and fabrication of SOFC components. They can be classified into three main groups: (1) the vapor-phase deposition, such as physical or chemical deposition, spray pyrolysis, plasma spray, etc.; (2) the liquid/colloidalphase deposition such as EPD, sol-gel, slip-casting, and dip-coating methods; and (3) the particle deposition/consolidation methods such as tape casting, screen-printing, etc. Physical vapor deposition techniques such as PLD and sputtering are generally expensive techniques from the point of view of equipment and have low deposition rates of a few nanometer per minute. But the quality of the films can be precisely controlled. Similarly, vacuum deposition techniques such as CVD, EVD, MOCVD, etc., also suffer from relatively high equipment cost and complexity, particularly when compared to more conventional particle deposition/consolidation methods of thin-film techniques that include tape casting, EPD, screen-printing, and transfer-printing. Despite these challenges, physical deposition and vacuum methods offer a number of unique advantages. Very thin, fully dense films can be produced on either porous or dense substrates, and can be formed at temperatures much lower than those required in traditional ceramic processing, avoiding unwanted interfacial reactions. Physical deposition and vacuum methods are also well suited to the formation of 
interlayers, where small grain sizes and thin layer thickness are required. Among the most unique aspects of physical and vacuum deposition is the ability to produce unique structures that are not otherwise achievable [61]. On the other hand, vacuum plasma spray (VPS) has the advantages of high deposition rate and the ability to be automated. However, there are two major concerns for the electrolyte deposited by VPS: anisotropic properties and significant variation in film thickness.

In contrast, the particle deposition/consolidation methods such as tape casting and screen-printing are popular, inexpensive, and are easily scaled up. The main issue is the thickness reduction. The minimum scale of the layers produced by state-of-the-art particle deposition/consolidation methods, such as tape casting, is several micrometers. On the other hand, slurry- or dip-coating techniques exhibit advantages of low capital cost and simplicity of equipment and can be applied to produce very thin and high-quality electrolyte films through the control of the surface microstructure of the substrate and the sol particle and particle size distribution [92]. Moreover, slurry or dip coating can be employed to fabricate thin electrolyte films not only for planar SOFCs, but also tubular SOFCs. The major concerns of the liquid- or colloidal-based deposition methods are the strain induced during drying or sintering, which results in some processing defects such as cracks, pores, or delamination. Thus, the most feasible way to overcoming these problems is by a multicoating process. However, the repeated processing approach may not be economically viable for the industrial fabrication and production of the SOFCs components. For the deposition processes involving colloidal solution or liquid slurry care should also be taken to prevent the solution from filtration into the porous substrates.

The choice of an appropriate thin-film deposition technique for SOFC applications is strongly influenced by the material to be deposited, the desired film quality and microstructure, process complexity and scalability, areas, shape, and geometry of the substrates to be deposited, and the cost of the instrumentation and operation. The SOFC technology has demonstrated much higher energy efficiency with extremely low pollutant emission as compared to conventional energy technologies, but the cost of the current SOFC systems is still prohibitively high for wide commercial applications. One of the major cost items is the cost of SOFC stack fabrication. The cost of thin electrolyte films, electrode coatings, and protective coatings for metallic interconnect is an important factor in the commercial realization of SOFC technologies. Nevertheless, in cases such as $\mu$-SOFCs the high film quality and ability to produce unusual configurations would outweigh other considerations for the selection of thin-film deposition techniques.

\section{ABBREVIATIONS}

AFL anode functional layer

ALD atomic layer deposition

APS atmosphere plasma spray

ASR area specific resistance

CCVD combustion chemical vapor deposition

CVD chemical vapor deposition

DC direct current

DMFCs direct methanol fuel cells

EB-PVD electron beam-physical vapor deposition

EPD electrophoretic deposition

ESD electrostatic spray deposition or electrostatic spray pyrolysis deposition

EVD electrochemical vapor deposition

FAVD flame-assisted vapor deposition

GDC Gd-doped ceria or $(\mathrm{Gd}, \mathrm{Ce}) \mathrm{O}_{2-\delta}$

LAFAD large area filtered arc deposition

LPCVD low pressure chemical vapor deposition

LSCo lanthanum strontium cobaltite or $(\mathrm{La}, \mathrm{Sr}) \mathrm{CoO}_{3}$ 


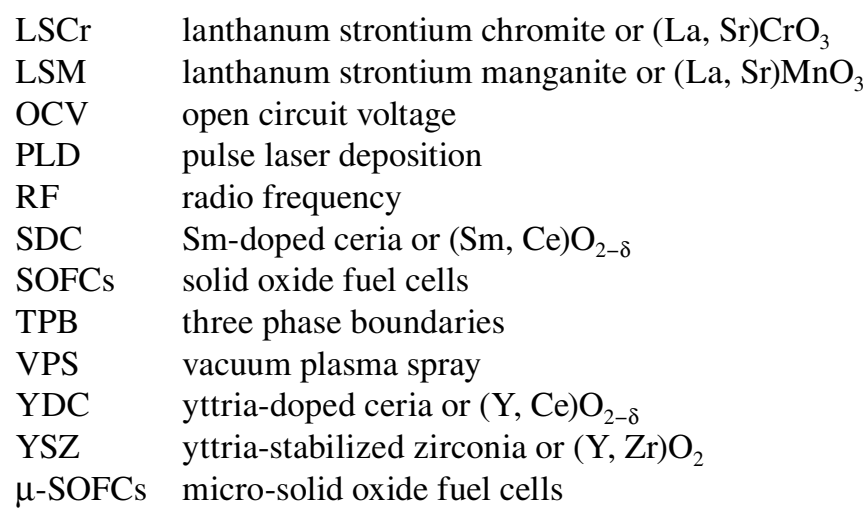

\section{REFERENCES}

1. Singhal S.C. 2002. Solid oxide fuel cells for stationary, mobile, and military applications. Solid State Ionics 152: 405-410.

2. Minh N.Q. 1993. Ceramic fuel-cells. Journal of the American Ceramic Society 76: 563-588.

3. Williams M.C., Strakey J.P., and Singhal S.C. 2004. US distributed generation fuel cell program. Journal of Power Sources 131: 79-85.

4. Jiang S.P. 2008. Development of lanthanum strontium manganite perovskite cathode materials of solid oxide fuel cells: A review. Journal of Materials Science 43: 6799-6833.

5. Yokokawa H., Sakai N., Horita T., Yamaji K., and Brito M.E. 2005. Electrolytes for solid-oxide fuel cells. Materials Research Society Bulletin 30: 591-595.

6. Jiang S.P. and Chan S.H. 2004. A review of anode materials development in solid oxide fuel cells. Journal of Materials Science 39: 4405-4439.

7. Gorte R.J., Vohs J.M., and McIntosh S. 2004. Recent developments on anodes for direct fuel utilization in SOFC. Solid State Ionics 175: 1-6.

8. Fergus J.W. 2005. Metallic interconnects for solid oxide fuel cells. Materials Science and Engineering A: Structural Materials: Properties, Microstructure and Processing 397: 271-283.

9. Will J., Mitterdorfer A., Kleinlogel C., Perednis D., and Gauckler L.J. 2000. Fabrication of thin electrolytes for second-generation solid oxide fuel cells. Solid State Ionics 131: 79-96.

10. Jiang S.P., Zhang S., and Zhen Y.D. 2005. Early interaction between Fe-Cr alloy metallic interconnect and Sr-doped $\mathrm{LaMnO}_{3}$ cathodes of solid oxide fuel cells. Journal of Materials Research 20: 747-758.

11. Jiang S.P., Liu Z.C., and Tian Z.Q. 2006. Layer-by-layer self-assembly of composite polyelectrolytenafion membranes for direct methanol fuel cells. Advanced Materials 18: 1068-1072.

12. Wasmus S. and Kuver A. 1999. Methanol oxidation and direct methanol fuel cells: a selective review. Journal of Electroanalytical Chemistry 461: 14-31.

13. Shao Z.P., Haile S.M., Ahn J., Ronney P.D., Zhan Z.L., and Barnett S.A. 2005. A thermally self-sustained micro solid-oxide fuel-cell stack with high power density. Nature 435: 795-798.

14. Beckel D., Bieberle-Hutter A., Harvey A., Infortuna A., Muecke U.P., Prestat M., Rupp J.L.M., and Gauckler L.J. 2007. Thin films for micro solid oxide fuel cells. Journal of Power Sources 173: 325-345.

15. Aizawa M., Kobayashi C., Yamane H., and Hirai T. 1993. Preparation of $\mathrm{ZRO}_{2}-\mathrm{Y}_{2} \mathrm{O}_{3}$ films by CVD using beta-diketone metal-chelates. Nippon Seramikkusu Kyokai Gakujutsu Ronbunshi-Journal of the Ceramic Society of Japan 101: 291-294.

16. Yamane H. and Hirai T. 1987. Preparation of $\mathrm{ZRO}_{2}$-film by oxidation of $\mathrm{ZRCL}_{4}$. Journal of Materials Science Letters 6: 1229-1230.

17. Yamane H. and Hirai T. 1989. Yttria stabilized zirconia transparent films prepared by chemical vapordeposition. Journal of Crystal Growth 94: 880-884.

18. Chour K.W., Chen J., and Xu R. 1997. Metal-organic vapor deposition of YSZ electrolyte layers for solid oxide fuel cell applications. Thin Solid Films 304: 106-112.

19. Itoh H., Mori M., Mori N., and Abe T. 1994. Production cost estimation of solid oxide fuel-cells. Journal of Power Sources 49: 315-332.

20. Hausmann D.M., Kim E., Becker J., and Gordon R.G. 2002. Atomic layer deposition of hafnium and zirconium oxides using metal amide precursors. Chemistry of Materials 14: 4350-4358. 
21. Shim J.H., Chao C.C., Huang H., and Prinz F.B. 2007. Atomic layer deposition of yttria-stabilized zirconia for solid oxide fuel cells. Chemistry of Materials 19: 3850-3854.

22. Su P.C., Chao C.C., Shim J.H., Fasching R., and Prinz F.B. 2008. Solid oxide fuel cell with corrugated thin film electrolyte. Nano Letters 8: 2289-2292.

23. Pal U.B. and Singhal S.C. 1990. Electrochemical vapor-deposition of yttria-stabilized zirconia films. Journal of the Electrochemical Society 137: 2937-2941.

24. Sasaki H., Otoshi S., Suzuki M., Sogi T., Kajimura A., Sugiura N., and Ippommatsu M. 1994. Fabrication of high-power density tubular type solid oxide fuel-cells. Solid State Ionics 72: 253-256.

25. Suzuki M. and Kajimura A. 1997. Geometrical analysis of SOFC anodes fabricated by electrochemical vapor deposition. Denki Kagaku 65: 859-864.

26. Ogumi Z., Ioroi T., Uchimoto Y., Takehara Z., Ogawa T., and Toyama K. 1995. Novel method for preparing nickel/YSZ cermet by a vapor-phase process. Journal of the American Ceramic Society 78: 593-598.

27. Kikuchi K., Tamazaki F., Okada K., and Mineshige A. 2006. Yttria-stabilized zirconia thin films deposited on NiO- $\left(\mathrm{Sm}_{2} \mathrm{O}_{3}\right)(0.1)\left(\mathrm{CeO}_{2}\right)(0.8)$ substrates by chemical vapor infiltration. Journal of Power Sources 162: 1053-1059.

28. Bae J.W., Park J.Y., Hwang S.W., Yeom G.Y., Kim K.D., Cho Y.A., Jeon J.S., and Choi D. 2000. Characterization of yttria-stabilized zirconia thin films prepared by radio frequency magnetron sputtering for a combustion control oxygen sensor. Journal of the Electrochemical Society 147: 2380-2384.

29. Srivastava P.K., Quach T., Duan Y.Y., Donelson R., Jiang S.P., Ciacchi F.T., and Badwal S.P.S. 1997. Electrode supported solid oxide fuel cells: Electrolyte films prepared by DC magnetron sputtering. Solid State Ionics 99: 311-319.

30. Wang L.S. and Barnett S.A. 1993. Sputter-deposited medium-temperature solid oxide fuel-cells with multilayer electrolytes. Solid State Ionics 61: 273-276.

31. Wanzenberg E., Tietz F., Panjan P., and Stover D. 2003. Influence of pre- and post-heat treatment of anode substrates on the properties of DC-sputtered YSZ electrolyte films. Solid State Ionics 159: 1-8.

32. Tsai T. and Barnett S.A. 1995. Bias sputter-deposition of dense yttria-stabilized zirconia films on porous substrates. Journal of the Electrochemical Society 142: 3084-3087.

33. Fedtke P., Wienecke M., Bunescu M.C., Barfels T., Deistung K., and Pietrzak M. 2004. Yttria-stabilized zirconia films deposited by plasma spraying and sputtering. Journal of Solid State Electrochemistry 8: 626-632.

34. Tao S.W. and Irvine J.T.S. 2002. Study on the structural and electrical properties of the double perovskite oxide $\mathrm{SrMn}_{0.5} \mathrm{Nb}_{0.5} \mathrm{O}_{3-\delta}$. Journal of Materials Chemistry 12: 2356-2360.

35. Ai N., Lu Z., Chen K.F., Huang X.Q., Du X.B., and Su W.H. 2007. Effects of anode surface modification on the performance of low temperature SOFCs. Journal of Power Sources 171: 489-494.

36. Kim S.D., Lee J.J., Moon H., Hyun S.H., Moon J., Kim J., and Lee H.W. 2007. Effects of anode and electrolyte microstructures on performance of solid oxide fuel cells. Journal of Power Sources 169: 265-270.

37. Huang H., Nakamura M., Su P.C., Fasching R., Saito Y., and Prinz F.B. 2007. High-performance ultrathin solid oxide fuel cells for low-temperature operation. Journal of the Electrochemical Society 154: B20-B24.

38. Uhlenbruck S., Jordan N., Sebold D., Buchkremer H.P., Haanappel V.A.C., and Stover D. 2007. Thin film coating technologies of $(\mathrm{Ce}, \mathrm{Gd}) \mathrm{O}_{2-\delta}$ interlayers for application in ceramic high-temperature fuel cells. Thin Solid Films 515: 4053-4060.

39. Horita T., Yamaji K., Ishikawa M., Sakai N., Yokokawa H., Kawada T., and Kato T. 1998. Active sites imaging for oxygen reduction at the $\mathrm{La}_{0.9} \mathrm{Sr}_{0.1} \mathrm{MnO}_{3-x}$ /yttria-stabilized zirconia interface by secondaryion mass spectrometry. Journal of the Electrochemical Society 145: 3196-3202.

40. Mizusaki J., Tagawa H., Saito T., Kamitani K., Yamamura T., Hirano K., Ehara S. et al. 1994. Preparation of nickel pattern electrodes on YSZ and their electrochemical properties in $\mathrm{H}_{2}-\mathrm{H}_{2} \mathrm{O}$ atmospheres. Journal of the Electrochemical Society 141: 2129-2134.

41. Lee C. and Bae J. 2008. Oxidation-resistant thin film coating on ferritic stainless steel by sputtering for solid oxide fuel cells. Thin Solid Films 516: 6432-6437.

42. Orlovskaya N., Coratolo A., Johnson C., and Gemmen R. 2004. Structural characterization of lanthanum chromite perovskite coating deposited by magnetron sputtering on an iron-based chromium-containing alloy as a promising interconnect material for SOFCs. Journal of the American Ceramic Society 87: 1981-1987.

43. Suzuki M., Sasaki H., and Kajimura A. 1997. Oxide ionic conductivity of doped lanthanum chromite thin film interconnectors. Solid State Ionics 96: 83-88.

44. Mengucci P., Barucca G., Caricato A.P., Di Cristoforo A., Leggieri G., Luches A., and Majnia G. 2005. Effects of annealing on the microstructure of yttria-stabilised zirconia thin films deposited by laser ablation. Thin Solid Films 478: 125-131. 
45. Nair B.N., Suzuki T., Yoshino Y., Gopalakrishnan S., Sugawara T., Nakao S., and Taguchi H. 2005. An oriented nanoporous membrane prepared by pulsed laser deposition. Advanced Materials 17: 1136-1140.

46. Infortuna A., Harvey A.S., and Gauckler L.J. 2008. Microstructures of CGO and YSZ thin films by pulsed laser deposition. Advanced Functional Materials 18: 127-135.

47. Joo J.H. and Choi G.M. 2006. Electrical conductivity of YSZ film grown by pulsed laser deposition. Solid State Ionics 177: 1053-1057.

48. Chen L., Chen C.L., Huang D.X., Lin Y., Chen X., and Jacobson A.J. 2003. High temperature electrical conductivity of epitaxial Gd-doped CeO2 thin films. Solid State Ionics 175:103-106.

49. Hobein B., Tietz F., Stover D., and Kreutz E.W. 2002. Pulsed laser deposition of yttria stabilized zirconia for solid oxide fuel cell applications. Journal of Power Sources 105: 239-242.

50. Meunier M., Izquierdo R., Hasnaoui L., Quenneville E., Ivanov D., Girard F., Morin F., Yelon A., and Paleologou M. 1998. Pulsed laser deposition of superionic ceramic thin films: deposition and applications in electrochemistry. Applied Surface Science 129: 466-470.

51. Koep E., Jin C.M., Haluska M., Das R., Narayan R., Sandhage K., Snyder R., and Liu M.L. 2006. Microstructure and electrochemical properties of cathode materials for SOFCs prepared via pulsed laser deposition. Journal of Power Sources 161: 250-255.

52. Koep E., Compson C., Liu M.L., and Zhou Z.P. 2005. A photolithographic process for investigation of electrode reaction sites in solid oxide fuel cells. Solid State Ionics 176: 1-8.

53. de Larramendi I.R., Ortiz N., Lopez-Anton R., de Larramendi J.I.R., and Rojo T. 2007. Structure and impedance spectroscopy of $\mathrm{La}_{0.6} \mathrm{Ca}_{0.4} \mathrm{Fe}_{0.8} \mathrm{Ni}_{0.2} \mathrm{O}_{3-\delta}$ thin films grown by pulsed laser deposition. Journal of Power Sources 171: 747-753.

54. Chen X., Wu N.J., and Ignatiev A. 1999. Structure and conducting properties of $\mathrm{La}_{1-x} \mathrm{Sr}_{x} \mathrm{CoO}_{3-\delta}$ films. Journal of the European Ceramic Society 19: 819-822.

55. Endo A., Ihara M., Komiyama H., and Yamada K. 1996. Cathodic reaction mechanism for dense Sr-doped lanthanum manganite electrodes. Solid State Ionics 86-8: 1191-1195.

56. Mikkelsen L., Pryds N., and Hendriksen P.V. 2007. Preparation of $\mathrm{La}_{0.8} \mathrm{Sr}_{0.2} \mathrm{Cr}_{0.97} \mathrm{~V}_{0.03} \mathrm{O}_{3-\delta}$ films for solid oxide fuel cell application. Thin Solid Films 515: 6537-6540.

57. Gannon P., Deibert M., White P., Smith R., Chen H., Priyantha W., Lucas J., and Gorokhousky V. 2008. Advanced PVD protective coatings for SOFC interconnects. Symposium on Materials in Clean Power Systems II held at the 2007 TMS Annual Conference and Exposition, 3991-4000.

58. Jung H.Y., Hong K.S., Kim H., Park J.K., Son J.W., Kim J., Lee H.W., and Lee J.H. 2006. Characterization of thin-film YSZ deposited via EB-PVD technique in anode-supported SOFCs. Journal of the Electrochemical Society 153: A961-A966.

59. Gibson I.R., Dransfield G.P., and Irvine J.T.S. 1998. Influence of yttria concentration upon electrical properties and susceptibility to ageing of yttria-stabilised zirconias. Journal of the European Ceramic Society 18: 661-667.

60. Laukaitis G. and Dudonis J. 2008. Microstructure of gadolinium doped ceria oxide thin films formed by electron beam deposition. Journal of Alloys and Compounds 459: 320-327.

61. Pederson L.R., Singh P., and Zhou X.D. 2006. Application of vacuum deposition methods to solid oxide fuel cells. Vacuum 80: 1066-1083.

62. Kulkarni A.A., Sampath S., Goland A., Herman H., Allen A.J., Ilavsky J., Gong W.Q., and Gopalan S. 2003 Plasma spray coatings for producing next-generation supported membranes. Symposium on Synthetic Clean Fuels from Natural Gas and Coal-Bed Methane, pp. 241-249.

63. Tai L.W. and Lessing P.A. 1991. Plasma spraying of porous-electrodes for a planar solid oxide fuel-cell. Journal of the American Ceramic Society 74: 501-504.

64. Li C.J., Li C.X., and Wang M. 2005. Effect of spray parameters on the electrical conductivity of plasmasprayed $\mathrm{La}_{1-x} \mathrm{Sr}_{x} \mathrm{MnO}_{3}$ coating for the cathode of SOFCs. Surface and Coatings Technology 198: $278-282$.

65. Lim D.P., Lim D.S., Oh J.S., and Lyo I.W. 2005. Influence of post-treatments on the contact resistance of plasma-sprayed $\mathrm{La}_{0.8} \mathrm{Sr}_{0.2} \mathrm{MnO}_{3}$ coating on SOFC metallic interconnector. Surface and Coatings Technology 200: 1248-1251.

66. Rambert S., McEvoy A.J., and Barthel K. 1999. Composite ceramic fuel cell fabricated by vacuum plasma spraying. Journal of the European Ceramic Society 19: 921-923.

67. Van herle J., McEvoy A.J., and Thampi K.R. 1994. Conductivity measurements of various yttria-stabilized zirconia samples. Journal of Materials Science 29: 3691-3701.

68. Ma X.Q., Zhang H., Dai J., Roth J., Hui R., Xiao T.D., and Reisner D.E. 2005. Intermediate temperature solid oxide fuel cell based on fully integrated plasma-sprayed components. Journal of Thermal Spray Technology 14: 61-66. 
69. Fauchais P., Rat V., Delbos U., Coudert J.F., Chartier T., and Bianchi L. 2005. Understanding of suspension DC plasma spraying of finely structured coatings for SOFC. IEEE Transactions on Plasma Science 33: 920-930.

70. Zheng R., Zhou X.M., Wang S.R., Wen T.L., and Ding C.X. 2005. A study of Ni+8YSZ/8YSZ/ $\mathrm{La}_{0.6} \mathrm{Sr}_{0.4} \mathrm{CoO}_{3-\delta}$ ITSOFC fabricated by atmospheric plasma spraying. Journal of Power Sources 140: 217-225.

71. White B.D., Kesler, O., and Rose, L. 2007. Electrochemical characterization of air plasma sprayed LSM/ YSZ composite cathodes on metallic interconnects. ECS Transactions 7: 1107-1114.

72. Vassen R., Kassner H., Stuke A., Hauler F., Hathiramani D., and Stover D. 2008. Advanced thermal spray technologies for applications in energy systems. Surface and Coatings Technology 202: 4432-4437.

73. Lang M., Henne R., Schaper S., and Schiller G. 2001. Development and characterization of vacuum plasma sprayed thin film solid oxide fuel cells. Journal of Thermal Spray Technology 10: 618-625.

74. Schiller G., Henne R., Lang M., Ruckdaschel R., and Schaper S. 2000. Fuel Cells Bulletin 3: 7.

75. Meier L.P., Urech L., and Gauckler L.J. 2004. Tape casting of nanocrystalline ceria gadolinia powder. Journal of the European Ceramic Society 24: 3753-3758.

76. Song J.H., Park S.I., Lee J.H., and Kim H.S. 2008. Fabrication characteristics of an anode-supported thin-film electrolyte fabricated by the tape casting method for IT-SOFC. Journal of Materials Processing Technology 198: 414-418.

77. Kim S.D., Hyun S.H., Moon J., Kim J.H., and Song R.H. 2005. Fabrication and characterization of anode-supported electrolyte thin films for intermediate temperature solid oxide fuel cells. Journal of Power Sources 139: 67-72.

78. Cai Z., Lan T.N., Wang S., and Dokiya M. 2002. Supported $\mathrm{Zr}(\mathrm{Sc}) \mathrm{O}-2$ SOFCs for reduced temperature prepared by slurry coating and co-firing. Solid State Ionics 152: 583-590.

79. Kim S.G., Yoon S.P., Nam S.W., Hyun S.H., and Hong S.A. 2002. Fabrication and characterization of a YSZ/YDC composite electrolyte by a sol-gel coating method. Journal of Power Sources 110: 222-228.

80. Xu X.Y., Xia C.R., Huang S.G., and Peng D.K. 2005. YSZ thin films deposited by spin-coating for IT-SOFCs. Ceramics International 31: 1061-1064.

81. Zhang Y.H., Huang X.Q., Lu Z., Ge X.D., Xu J.H., Xin X.S., Sha X.Q., and Su W.H. 2006. Effect of starting powder on screen-printed YSZ films used as electrolyte in SOFCs. Solid State Ionics 177: 281-287.

82. Chu W.F. 1992. Thin-film and thick-film solid ionic devices. Solid State Ionics 52: 243-248.

83. Chen K.F., Lu Z., Ai N., Huang X.Q., Zhang Y.H., Ge X.D., Xin X.S., Chen X.J., and Su W.H. 2007. Fabrication and performance of anode-supported YSZ films by slurry spin coating. Solid State Ionics 177: 3455-3460.

84. Chen Y.Y. and Wei W.C.J. 2006. Processing and characterization of ultra-thin yttria-stabilized zirconia (YSZ) electrolytic films for SOFC. Solid State Ionics 177: 351-357.

85. Wang Z.C., Weng W.J., Chen K., Shen G., Du P.Y., and Han G.R. 2008. Preparation and performance of nanostructured porous thin cathode for low-temperature solid oxide fuel cells by spin-coating method. Journal of Power Sources 175: 430-435.

86. Wang J.M., Lu Z., Huang X.Q., Chen K.F., Ai N., Hu J.Y., and Su W.H. 2007. YSZ films fabricated by a spin smoothing technique and its application in solid oxide fuel cell. Journal of Power Sources 163: 957-959.

87. Matus Y.B., De Jonghe L.C., Jacobson C.P., and Visco S.J. 2005. Metal-supported solid oxide fuel cell membranes for rapid thermal cycling. Solid State Ionics 176: 443-449.

88. Tucker M.C., Lau G.Y., Jacobson C.P., DeJonghe L.C., and Visco S.J. 2007. Performance of metalsupported SOFCs with infiltrated electrodes. Journal of Power Sources 171: 477-482.

89. Wang C.H., Worrell W.L., Park S., Vohs J.M., and Gorte R.J. 2001. Fabrication and performance of thinfilm YSZ solid oxide fuel cells. Journal of the Electrochemical Society 148: A864-A868.

90. Zhang L., He H.Q., Kwek W.R., Ma J., Tang E.H., and Jiang S.P. 2009. Fabrication and characterization of anode-supported tubular solid-oxide fuel cells by slip casting and dip coating techniques. Journal of the American Ceramic Society 92: 302-310.

91. Yamaguchi T., Suzuki T., Shimizu S., Fujishiro Y., and Awano M. 2007. Examination of wet coating and co-sintering technologies for micro-SOFCs fabrication. Journal of Membrane Science 300: 45-50.

92. Van Gestel T., Sebold D., Meulenberg W.A., and Buchkremer H.P. 2008. Development of thin-film nanostructured electrolyte layers for application in anode-supported solid oxide fuel cells. Solid State Ionics 179: 428-437.

93. Wang Z.H., Sun K.N., Shen S.Y., Zhang N.Q., Qiao J.S., and Xu P. 2008. Preparation of YSZ thin films for intermediate temperature solid oxide fuel cells by dip-coating method. Journal of Membrane Science 320: 500-504. 
94. Liu M.F., Dong D.H., Zhao F., Gao J.F., Ding D., Liu X.Q., and Meng G.Y. 2008. High-performance cathode-supported SOFCs prepared by a single-step co-firing process. Journal of Power Sources 182: 585-588.

95. Zhang Y.H., Liu J., Huang X.Q., Lu Z., and Su W.H. 2008. Performance evaluation of thin membranes solid oxide fuel cell prepared by pressure-assisted slurry-casting. International Journal of Hydrogen Energy 33: 775-780.

96. Serra J.M., Vert V.B., Buchler O., Meulenberg W.A., and Buchkremer H.P. 2008. IT-SOFC supported on mixed oxygen ionic-electronic conducting composites. Chemistry of Materials 20: 3867-3875.

97. Reitz T.L. and Xiao H.M. 2006. Characterization of electrolyte-electrode interlayers in thin film solid oxide fuel cells. Journal of Power Sources 161: 437-443.

98. Dunn B., Farrington G.C., and Katz B. 1993. Sol-gel approaches for solid electrolytes and electrode materials. 9th International Conference on Solid State Ionics, the Hague, Netherlands, pp. 3-10.

99. Mehta K., Xu R., and Virkar A.V. 1998. Two-layer fuel cell electrolyte structure by sol-gel processing. Journal of Sol-Gel Science and Technology 11: 203-207.

100. Lee E.A., Lee S., Hwang H.J., and Moon J.W. 2006. Sol-gel derived $\left(\mathrm{La}_{0.8} \mathrm{M}_{0.2}\right) \mathrm{CrO}_{3}(\mathrm{M}=\mathrm{Ca}$, Sr) coating layer on stainless-steel substrate for use as a separator in intermediate-temperature solid oxide fuel cell. Journal of Power Sources 157: 709-713.

101. Zhang X.G., Robertson M., Deces-Petit C., Xie Y.S., Hui R., Yick S., Styles E., Roller J., Kesler O., Maric R., and Ghosh D. 2006. NiO-YSZ cermets supported low temperature solid oxide fuel cells. Journal of Power Sources 161: 301-307.

102. Xia C.R., Chen F.L., and Liu M.L. 2001. Reduced-temperature solid oxide fuel cells fabricated by screen printing. Electrochemical and Solid State Letters 4: A52-A54.

103. Joo J.H. and Choi G.M. 2008. Simple fabrication of micro-solid oxide fuel cell supported on metal substrate. Journal of Power Sources 182: 589-593.

104. Ishihara T., Sato K., and Takita Y. 1996. Electrophoretic deposition of $\mathrm{Y}_{2} \mathrm{O}_{3}$-stabilized $\mathrm{ZrO}_{2}$ electrolyte films in solid oxide fuel cells. Journal of the American Ceramic Society 79: 913-919.

105. Ishihara T., Shimose K., Kudo T., Nishiguchi H., Akbay T., and Takita Y. 2000. Preparation of yttriastabilized zirconia thin films on strontium-doped $\mathrm{LaMnO}_{3}$ cathode substrates via electrophoretic deposition for solid oxide fuel cells. Journal of the American Ceramic Society 83: 1921-1927.

106. Mathews T., Rabu N., Sellar J.R., and Muddle B.C. 2000. Fabrication of $\mathrm{La}_{1-x} \mathrm{Sr}_{x} \mathrm{Ga}_{1-y} \mathrm{Mg}_{y} \mathrm{O}_{3-(x+y)} / 2$ thin films by electrophoretic deposition and its conductivity measurement. Solid State Ionics 128: 111-115.

107. Matsuda M., Ohara O., Murata K., Ohara S., Fukui T., and Miyake M. 2003. Electrophoretic fabrication and cell performance of dense $\mathrm{Sr}$ - and $\mathrm{Mg}$-doped $\mathrm{LaGaO}_{3}$-based electrolyte films. Electrochemical and Solid State Letters 6: A140-A143.

108. Besra L., Compson C., and Liu M.L. 2007. Electrophoretic deposition on non-conducting substrates: The case of YSZ film on NiO-YSZ composite substrates for solid oxide fuel cell application. Journal of Power Sources 173: 130-136.

109. Chen F.L. and Liu M.L. 2001. Preparation of yttria-stabilized zirconia (YSZ) films on $\mathrm{La}_{0.85} \mathrm{Sr}_{0.15} \mathrm{MnO}_{3}$ (LSM) and LSM-YSZ substrates using an electrophoretic deposition (EPD) process. Journal of the European Ceramic Society 21: 127-134.

110. Peng Z.Y. and Liu M.L. 2001. Preparation of dense platinum-yttria stabilized zirconia and yttria stabilized zirconia films on porous $\mathrm{La}_{0.9} \mathrm{Sr}_{0.1} \mathrm{MnO}_{3}$ (LSM) substrates. Journal of the American Ceramic Society 84: 283-288.

111. Sarkar P., De D., and Rho H. 2004. Synthesis and microstructural manipulation of ceramics by electrophoretic deposition. Journal of Materials Science 39: 819-823.

112. Besra L. and Liu M. 2007. A review on fundamentals and applications of electrophoretic deposition (EPD). Progress in Materials Science 52: 1-61.

113. Hosomi T., Matsuda M., and Miyake M. 2007. Electrophoretic deposition for fabrication of YSZ electrolyte film on non-conducting porous NiO-YSZ composite substrate for intermediate temperature SOFC. Journal of the European Ceramic Society 27: 173-178.

114. Cherng J.S., Sau J.R., and Chung C.C. 2008. Aqueous electrophoretic deposition of YSZ electrolyte layers for solid oxide fuel cells. Journal of Solid State Electrochemistry 12: 925-933.

115. Will J., Hruschka M.K.M., Gubler L., and Gauckler L.J. 2001. Electrophoretic deposition of zirconia on porous anodic substrates. Journal of the American Ceramic Society 84: 328-332.

116. Besra L., Zha S.W., and Liu M.L. 2006. Preparation of NiO-YSZ/YSZ bi-layers for solid oxide fuel cells by electrophoretic deposition. Journal of Power Sources 160: 207-214. 
117. Jean J.H., Chang C.R., and Chen Z.C. 1997. Effect of densification mismatch on camber development during cofiring of nickel-based multilayer ceramic capacitors. Journal of the American Ceramic Society 80: 2401-2406.

118. Park S., Gorte R.J., and Vohs J.M. 2001. Tape cast solid oxide fuel cells for the direct oxidation of hydrocarbons. Journal of the Electrochemical Society 148: A443-A447.

119. Sofie S.W. 2007. Fabrication of functionally graded and aligned porosity in thin ceramic substrates with the novel freeze-tape-casting process. Journal of the American Ceramic Society 90: 2024-2031.

120. Minh N.Q. 1988. Development of monolithic solid oxide fuel-cells for aerospace applications. Journal of the Electrochemical Society 135: C344-C344.

121. Singh P. and Minh N.Q. 2004. Solid oxide fuel cells: Technology status. International Journal of Applied Ceramic Technology 1: 5-15.

122. Minh N.Q. 2004. Solid oxide fuel cell technology-features and applications. Solid State Ionics 174: 271-277.

123. Xia C.R. and Liu M.L. 2001. A simple and cost-effective approach to fabrication of dense ceramic membranes on porous substrates. Journal of the American Ceramic Society 84: 1903-1905.

124. Xia C.R. and Liu M.L. 2002. Microstructures, conductivities, and electrochemical properties of $\mathrm{Ce}_{0.9} \mathrm{Gd}_{0.1} \mathrm{O}_{2}$ and GDC-Ni anodes for low-temperature SOFCs. Solid State Ionics 152: 423-430.

125. Xia C.R. and Liu M.L. 2001. Low-temperature SOFCs based on $\mathrm{Gd}_{0.1} \mathrm{Ce}_{0.9} \mathrm{O}_{1.95}$ fabricated by dry pressing. Solid State Ionics 144: 249-255.

126. Leng Y.J., Chan S.H., Jiang S.P., and Khor K.A. 2004. Low-temperature SOFC with thin film GDC electrolyte prepared in situ by solid-state reaction. Solid State Ionics 170: 9-15.

127. Perednis D. and Gauckler L.J. 2005. Thin film deposition using spray pyrolysis. Journal of Electroceramics 14: 103-111.

128. Perednis D. and Gauckler L.J. 2004. Solid oxide fuel cells with electrolytes prepared via spray pyrolysis. Solid State Ionics 166: 229-239.

129. Rupp J.L.M., Infortuna A., and Gauckler L.J. 2006. Microstrain and self-limited grain growth in nanocrystalline ceria ceramics. Acta Materialia 54: 1721-1730.

130. Rupp J.L.M., Drobek T., Rossi A., and Gauckler L.J. 2007. Chemical analysis of spray pyrolysis gadolinia-doped ceria electrolyte thin films for solid oxide fuel cells. Chemistry of Materials 19: 1134-1142.

131. Setoguchi T., Sawano M., Eguchi K., and Arai H. 1990. Application of the stabilized zirconia thin-film prepared by spray pyrolysis method to SOFC. Solid State Ionics 40-41: 502-505.

132. Patil B.B., Ganesan V., and Pawar S.H. 2008. Studies on spray deposited NiO-SDC composite films for solid oxide fuel cells. Journal of Alloys and Compounds 460: 680-687.

133. Charpentier P., Fragnaud P., Schleich D.M., and Gehain E. 2000. Preparation of thin film SOFCs working at reduced temperature. Solid State Ionics 135: 373-380.

134. Choy K.L., Charojrochkul S., and Steele B.C.H. 1997. Fabrication of cathode for solid oxide fuel cells using flame assisted vapour deposition technique. Solid State Ionics 96: 49-54.

135. Charojrochkul S., Choy K.L., and Steele B.C.H. 1999. Cathode electrolyte systems for solid oxide fuel cells fabricated using flame assisted vapour deposition technique. Solid State Ionics 121: 107-113.

136. Liu Y., Compson C., and Liu M.L. 2004. Nanostructured and functionally graded cathodes for intermediate temperature solid oxide fuel cells. Journal of Power Sources 138: 194-198.

137. Fu C.Y., Chang C.L., Hsu C.S., and Hwang B.H. 2005. Electrostatic spray deposition of $\mathrm{La}_{0.8} \mathrm{Sr}_{0.2} \mathrm{Co}_{0.2} \mathrm{Fe}_{0.8} \mathrm{O}_{3}$ films. Materials Chemistry and Physics 91: 28-35.

138. Jaworek A. 2007. Electrospray droplet sources for thin film deposition. Journal of Materials Science 42: 266-297.

139. Nomura H., Parekh S., Selman J.R., and Al-Hallaj S. 2005. Fabrication of YSZ electrolyte using electrostatic spray deposition (ESD): I - a comprehensive parametric study. Journal of Applied Electrochemistry 35: 61-67.

140. Princivalle A. and Djurado E. 2008. Nanostructured LSM/YSZ composite cathodes for IT-SOFC: A comprehensive microstructural study by electrostatic spray deposition. Solid State Ionics 179: 1921-1928.

141. Hsu C.S., Hwang B.H., Xie Y., and Zhang X. 2008. Enhancement of solid oxide fuel cell performance by $\mathrm{La}_{0.6} \mathrm{Sr}_{0.4} \mathrm{Co}_{0.2} \mathrm{Fe}_{0.8} \mathrm{O}_{3-\delta}$ double-layer cathode. Journal of the Electrochemical Society 155 : B1240-B1243.

142. Chen X., Wu N.J., Smith L., and Ignatiev A. 2004. Thin-film heterostructure solid oxide fuel cells. Applied Physics Letters 84: 2700-2702. 


\section{AUTHOR QUERIES}

[AQ1] Please check author names, article title, and symposium title for Ref. [62].

[AQ2] Please provide the article title for Ref. 74. 